\title{
Festejando a la madre y al bebé en el cuarentavo día el programa post-parto de Sfax, Tunicia
}

\author{
Francine Coeytaux \\ Population Council \\ Beverly Winikoff \\ Population Council
}

Follow this and additional works at: https://knowledgecommons.popcouncil.org/departments_sbsr-pgy

Part of the Family, Life Course, and Society Commons, International Public Health Commons, Maternal and Child Health Commons, Public Health Education and Promotion Commons, and the Women's Health Commons How does access to this work benefit you? Let us know!

\section{Recommended Citation}

Coeytaux, Francine and Beverly Winikoff. 1989. "Festejando a la madre y al bebé en el cuarentavo día el programa post-parto de Sfax, Tunicia," Quality/Calidad/Qualité no. 1. New York: Population Council. 
Festejando a la Madre y al Bebé en el Cuarentavo Día: El Programa Post Parto de Sfax, Tunicia

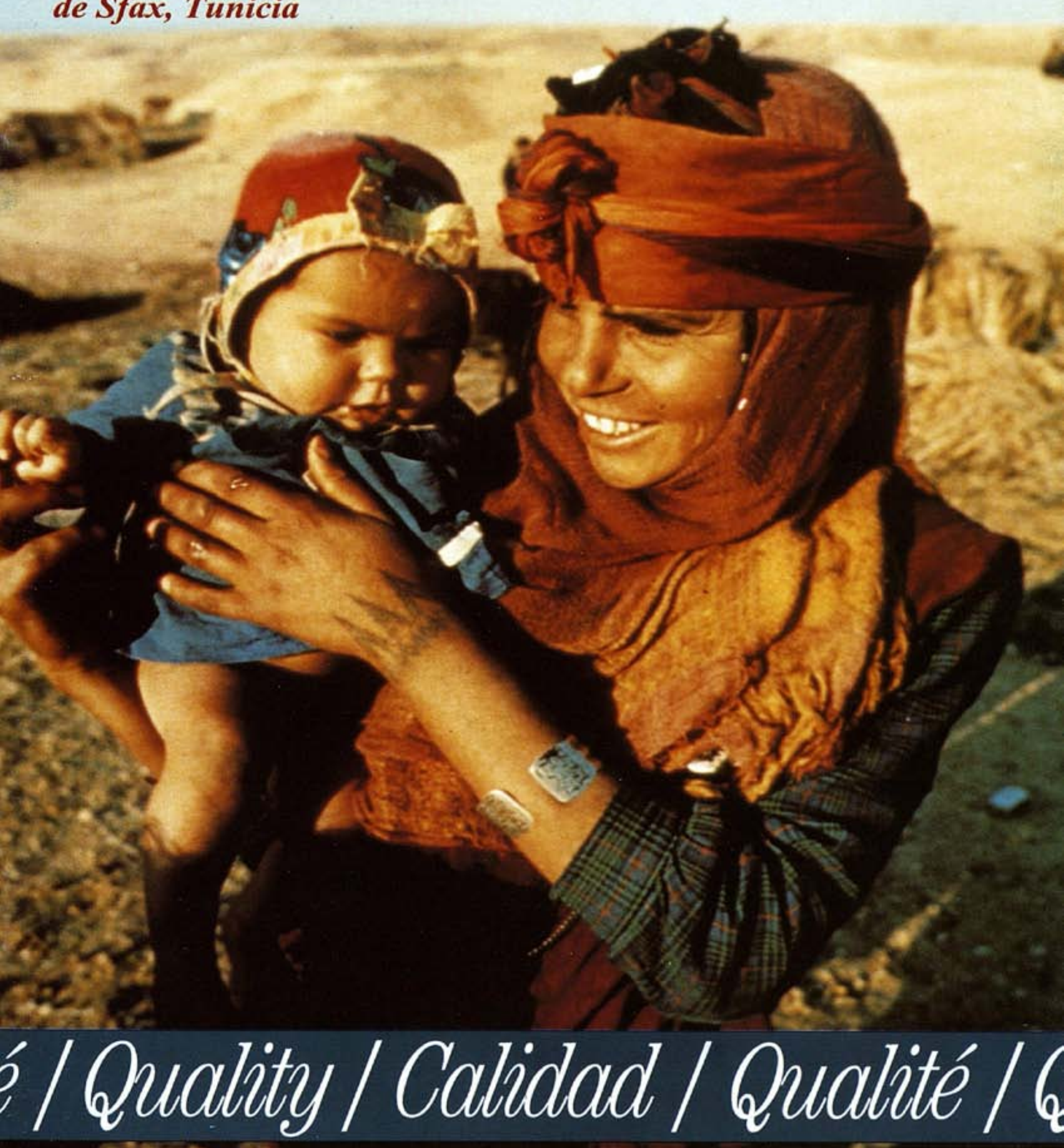


Calidad/Quality/Qualité, una publicación del Population Council, resalta ejemplos de programas de planificación familiar y salud reproductiva que se esmeran por dar servicios de alta calidad. Esta serie es parte del Programa Robert H. Ebert en Temas Críticos en Salud Reproductiva y Población, el cual, mediante esfuerzos científicos y prácticos, busca mejorar y expandir el alcance y la calidad de los servicios en salud reproductiva. Los fundamentos filosóficos del programa y de esta serie, parten de que las mujeres y sus parejas tienen derecho a recibir de los proveedores de servicios de salud reproductiva un trato respetuoso, información, continuidad en la atención y la presentación de opciones para elegir un método anticonceptivo. Los folletos reflejan uno de estos elementos necesarios para mejorar la calidad de los programas de planificación familiar.

Los proyectos para la documentación de la serie Calidad/Quality/Qualité los selecciona un Comité Asesor integrado por personas con una amplia experiencia en el campo de la salud reproductiva y comprometidas con el mejoramiento de la calidad de atención de los servicios. Estos proyectos muestran avances importantes en uno o más de los siguientes aspectos: ampliar la variedad de métodos anticonceptivos y tecnologias disponibles; suministrar la información que los clientes necesitan para tomar decisiones informadas sobre el manejo de su propia salud; reforzar la calidad de la interacción cliente/ proveedor y favorecer el contacto constante entre proveedores y clientes; ensayar estrategias innovadoras para mejorar la capacidad gerencial de los directivos y las habilidades técnicas de los proveedores de servicios de diferentes niveles de atención; expandir la gama de servicios y la información suministrada más allá de lo que usualmente se llama "planificación familiar"; y proporcionar atención en salud reproductiva a grupos desfavorecidos y sin acceso a los servicios.

Ninguno de los proyectos documentados en estas series se ofrece como un modelo para replicar. Por el contrario, cada uno está presentado como un ejemplo creativo inusual de valores, objetivos e implementación. Las "experiencias de aprendizaje" demuestran la actitud de autocrítica que se requiere para anticipar las necesidades de servicios de los clientes y encontrar los medios para satisfacerlas con los recursos existentes. Esta postura reflexiva se ejemplifica mediante la voluntad de responder tanto a cambios de las necesidades de los clientes como de transformaciones sociales y económicas más amplias que afectan a las sociedades. Creemos que documentar las decisiones cruciales que estos programas han tomado ayudará a reforzar la creencia de que la satisfacción personal con los servicios de salud reproductiva, está íntimamente ligada con el cumplimento de metas sociales más amplias en salud y población.

La publicación de la edición original en inglés de Calidad/Quality/Qualité fue posible gracias al apoyo de la Fundación Ford, la Fundación John D. y Catherine T. MacArthur y el Fondo de las Naciones Unidas para Actividades de Población (FNUAP).

La edición en español fue financiada por el proyecto INOPAL III (Investigación Operativa y Asistencia Técnica en Planificación Familiar y Salud Reproductiva en América Latina y el Caribe) que a su vez es financiado por la Agencia Internacional para el Desarrollo de los Estados Unidos (USAID) mediante el contrato No. CCP-95-C-00-00007-00.

Traducción al español:

Responsable de la publicación:
Maria Elena Casanova

Silvia Llaguno 


\title{
Festejando a la Madre y al Bebé en el Cuarentavo Día \\ El Programa Post-parto de Sfax, Tunicia
}

\author{
por Francine Coeytaux
}

\author{
Introducción y Palabras Finales por la \\ Dra. Beverly Winikoff
}

\section{INTRODUCCION}

Durante años, la mayoría de los servicios de planificación familiar han dado por hecho que las mujeres estarán dispuestas a usar anticonceptivos inmediatamente después del nacimiento de un bebé; que después de la experiencia del alumbramiento, con todas sus incomodidades, las mujeres estarán muy motivadas a evitar otro embarazo, trabajo de parto y alumbramiento. También se ha supuesto que no puede confiarse en que las mujeres regresarán a solicitar servicios de planificación familiar y, por lo tanto, deben ser "captadas" mientras están aún en manos del personal médico.

De hecho, ninguna de estas dos suposiciones es realista. En el primer caso, un enfoque centrado únicamente en la anticoncepción descuida al menos dos preocupaciones que las madres tienen en el periodo de post-parto, que descarta su interés potencial en evitar otro nacimiento: el bienestar del bebé recién nacido y las propias necesidades de salud. Algunas de las cuestiones que más preocupan a las madres en el período de post-parto se refieren a cómo solucionar los problemas de lactancia y destete. Las investigaciones muestran que la mayoría de las mujeres desean amamantar y aprecian los beneficios de salud que esto aporta al bebé. Sin embargo, paradójicamente, la lactancia es con frecuencia imposible y rara vez se practica de manera exclusiva, aún entre las madres en los países en desarrollo. Esto se debe, en parte, a la poca información y, en parte, debido a los obstáculos médicos o institucionales que se presentan dentro del mismo sistema de salud, tales como la separación de la madre y el bebé, la alimentación con biberón, la información incorrecta de parte de los profesionales de la salud y el proporcionar muestras de fórmula a las madres. Además, la presión del personal de salud para que practiquen la anticoncepción inmediatamente después del parto, con frecuencia desanima a las madres para seguir amamantando.

Un programa que concibe los servicios de salud post-parto más allá del estrecho enfoque de la anticoncepción podría responder a las necesidades de las nuevas madres de manera más significativa y determinar, al mismo tiempo, el momento y el tipo más adecuado de servicios de planificación familiar para este grupo. Desafortunadamente, aún cuando los servicios tratan de atender las preocupaciones de 
las madres, éstos se ven con frecuencia obstaculizados por la falta de conocimientos de los profesionales de la salud sobre la anticoncepción durante la lactancia.

La segunda suposición, que el periodo de post-parto es el único momento en que se puede captar a las mujeres, ya que no solicitarán servicios médicos después del parto, se contradice con los hechos. Los programas bien manejados que ofrecen los servicios deseados son como un imán para las clientes, como se muestra en el estudio del caso que sigue. Además, aunque más mujeres en países en desarrollo están dando a luz en hospitales, su estancia es tan breve (con frecuencia 6-12 horas), que tratar de proporcionarles servicios anticonceptivos significativos en ese contexto simplemente no es factible.

Además, cuando las mujeres regresan por servicios de planificación familiar, pueden encontrarse con nuevos obstáculos. Los administradores de programas con frecuencia abruman a los prestadores de servicios con protocolos innecesariamente restrictivos que impiden atender a muchas mujeres que desean planificación familiar. Esto puede tener consecuencias serias tanto para las madres como para sus bebés, ya que muchas mujeres de paises en desarrollo necesitarán iniciar la anticoncepción en algún momento durante la lactancia, para evitar un nuevo embarazo no espaciado.

En resumen, los programas post-parto históricamente han sufrido de las siguientes deficiencias: 1) la falta de conocimientos de los profesionales de salud y el no tomar en cuenta las inquietudes de las madres en el diseño de los servicios post-parto; 2) la falta de conocimientos de los profesionales de la salud sobre la lactancia materna; 3 ) consejería y servicios de anticoncepción inadecuados específicamente para mujeres lactantes; 4) la falta de coordinación entre los servicios de salud infantil y de planificación familiar, y 5) que no se haya diseñado un paquete que ofrezca servicios de salud a madres y bebés al mismo tiempo (vacunas al bebé sano, apoyo a la lactancia, servicios anticonceptivos para las madres).

El siguiente estudio de caso del Programa Post-parto del Cuarentavo Día en Sfax, Tunicia, demuestra algunas nuevas y exitosas maneras de proporcionar servicios de salud adecuados a madres y bebés en el periodo post-parto. 


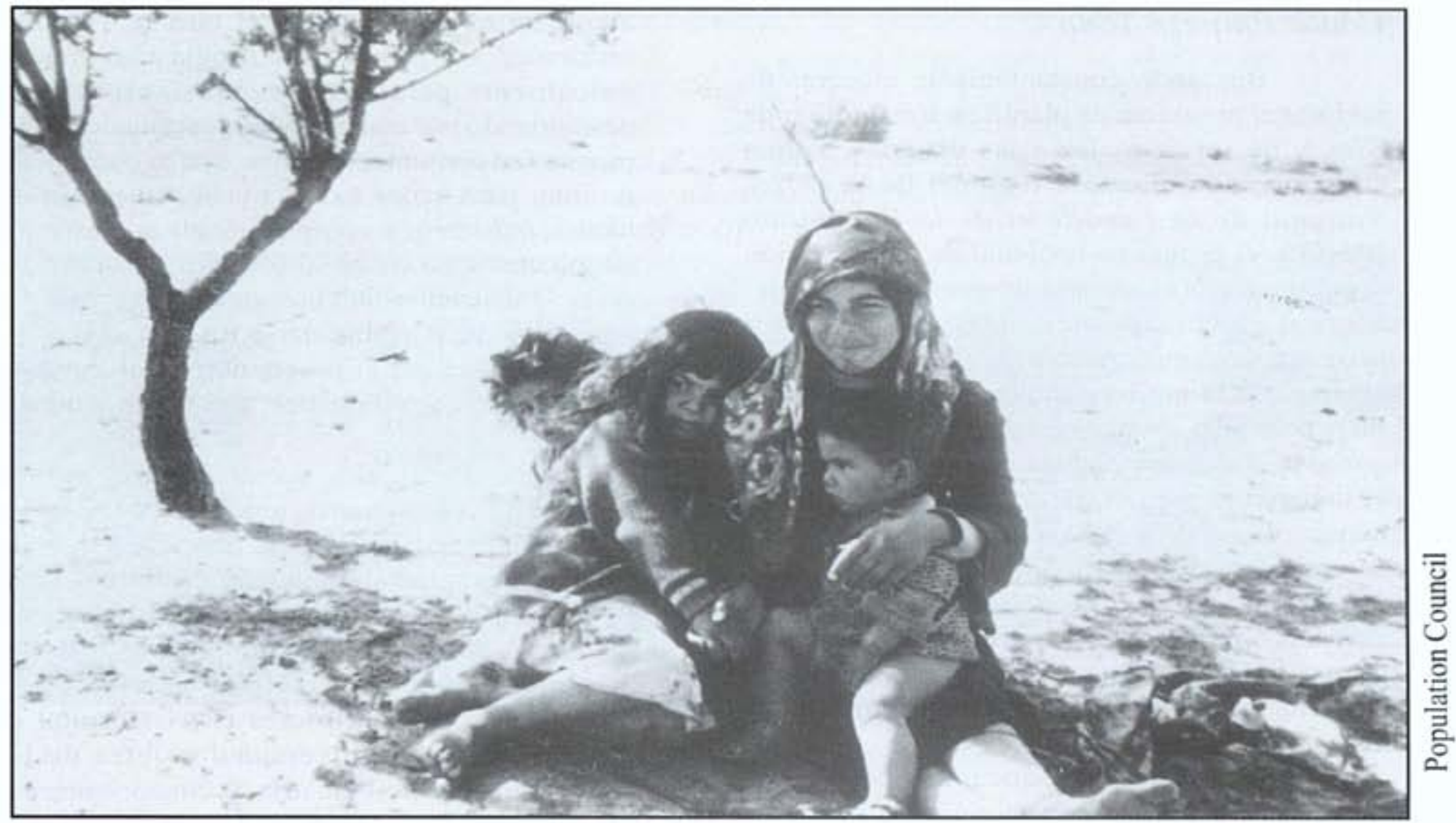

\section{Antecedentes}

Sfax, la segunda ciudad más importante de Tunicia, con una población de casi 400,000 habitantes, se localiza a orillas del Mar Mediterráneo aproximadamente 270 kilómetros al sur de Túnez, la capital. Un vibrante puerto industrial y pesquero, donde el paisaje urbano pronto da paso a los huertos de olivos. Conocida como la "capital del sur", Sfax es un centro urbano importante, que sirve a gente de la frontera rural del Sahara y a los del norte que llegan por comercio y servicios.

La principal escuela de medicina de Tunicia se encuentra en Sfax y el Hospital de Enseñanza de la Universidad sirve como principal punto de referencia para todo el sur del país. Otro servicio que atrae gente de las áreas circundantes a la ciudad es el Hospital de Maternidad y Neonatología de Sfax. En este hospital de 136 camas, llamado el Centre de Maternité et Neonatologie de Sfax, se atienden un promedio de 30-40 partos por dia, o aproximadamente 11,000 nacimientos al año, que representan el 65 por ciento de todos los nacimientos en la región. Sólo el 25 por ciento de las mujeres en la región de Sfax dan a luz en su casa, sin asistencia profesional (en comparación con una tasa nacional de 33 por ciento de partos en casa). El 10 por ciento restante dan a luz en distintos centros de salud rurales y clínicas privadas.

En 1983, en un esfuerzo por promover la planificación familiar y proporcionar atención al bebé sano, el Hospital de Maternidad y Neonatología de Sfax puso en marcha un innovador programa post-parto que programaba una visita de seguimiento para todas las madres y sus bebés, 40 dias después del nacimiento. El programa demostró ser exitoso inmediatamente al lograr que las mujeres regresaran para su seguimiento, y para 1987 los registros del hospital indicaban que el 83 por ciento de las mujeres que habian dado a luz en la maternidad de Sfax ese año habian regresado para su visita post-parto. El éxito del programa se atribuye principalmente a dos factores importantes incorporados a este diseño: 1) la cita es para ambos, el bebé y la madre, proporcionando servicios a los dos al mismo tiempo y en el mismo lugar, y 2) la cita se programa el cuarentavo día después del parto, un dia de gran significado cultural y religioso en Tunicia para la madre y su bebé. 


\section{Cómo Empezó Todo}

Buscando constantemente maneras de mejorar el programa de planificación familiar de Sfax y de servir mejor a las usuarias, Fatma Gargouri, coordinadora regional de la Office National de la Famille et de la Population (ONFP)- el programa nacional de planificación familiar- queria asegurarse de que todas las mujeres que estuvieran interesadas en prevenir o retrasar su siguiente embarazo iniciaran la práctica de la anticoncepción tan pronto como fuera adecuado, después del parto. Ella reconoció que el hospital de maternidad de Sfax podría ser el lugar ideal para lograrlo. El tener a un gran número de mujeres en edad reproductiva reunidas en un lugar sería una oportunidad perfecta para informarlas y educarlas sobre la planificación familiar. Pero informar a las mujeres sobre planificación familiar no era suficiente. Necesitaban también tener acceso inmediato a los servicios.

Los servicios de educación post-parto existian (y siguen proporcionándose) en casi todos los hospitales tunecinos manejados y atendidos por la ONFP. Dentro del programa de la ONFP, los educadores de salud han sido asignados a los hospitales de maternidad, para hablar con las mujeres que dan a luz en el hospital sobre las opciones anticonceptivas. E1 seguimiento, sin embargo, ha sido mínimo porque el personal del hospital tiende a ver la prestación de servicios anticonceptivos como una responsabilidad del programa de planificación familiar. Este punto de vista se refuerza en la mayor parte del país por el hecho de que los servicios pediátricos y de planificación familiar se encuentran en edificios separados de las maternidades. El centro en $\mathrm{S} f a x$ es una excepción. Es uno de cuatro hospitales en el pais que albergan servicios de ginecobstetricia y de pediatría bajo el mismo techo. Todo un piso en cada uno de estos cuatro hospitales está ahora reservado para los servicios de planificación familiar.

La proximidad física solamente, sin embargo, no cubrió la brecha entre los diversos servicios. El personal de la maternidad seguía considerando a la planificación familiar como la responsabilidad de otros, y la actitud del personal de planificación familiar era: "Ahora que ya atendiste el parto, danos al cliente." Como resultado, cada programa se dirigía a las mujeres únicamente para sus servicios respectivos, descuidando por completo las necesidades de las mujeres en conjunto. Gargouri estaba convencida de que, para tener éxito, un nuevo programa tendría que integrar completamente la prestación de los servicios de planificación familiar a los servicios normales del hospital, y se empeñó en lograr que el personal del hospital considerara su propia función el proporcionar información de planificación familiar y recetar anticonceptivos.

Semejante modelo necesitaba de un espíritu de equipo y la voluntad de todos los involucrados de considerar y satisfacer ampliamente las necesidades tanto de la madre como del bebé. El programa, por lo tanto, no podria haberse iniciado sin el interés y el compromiso de los médicos Ahmed y Saida Rekik -marido y mujer-, quienes son profesores en el Hospital de Enseñanza de la Universidad y Jefes de los Departamentos de Pediatría y Ginecobstetricia del Hospital de Maternidad y Neonatología, respectivamente. La idea de atender al bebé junto con la madre fue del pediatra Ahmed Rekik, quien estaba convencido de que la salud reproductiva de la madre y el espaciamiento de los nacimientos benefician directamente al bebé y a la madre. Pronto su esposa, Saida Rekik, a cargo del departamento de ginecobstetricia en el hospital, se unió al equipo. Ambos reconocieron, desde sus diferentes perspectivas, las posibilidades prácticas de tratar a la madre y el bebé como un par interrelacionado, la couple mere-enfant (pareja madre-bebé).

Lo que surgió fue una nueva visión de los servicios post-parto en el hospital. A las mujeres se les invitaba a regresar el cuarentavo día después del nacimiento a una clinica aparte, dentro del hospital, donde se proporcionarian servicios para ambos madres y bebés al mismo tiempo, en el mismo lugar. Mientras que antes a las mujeres se les invitaba a regresar a una consulta de planificación familiar cuando les fuera conveniente, el nuevo programa no sólo capitalizaria una fecha que tenia un significado para la madre y sería recordada fácilmente (véase la sección siguiente) sino que, quizás más importante, respondería a la inquietud de la madre por la salud de su bebé, que es una 


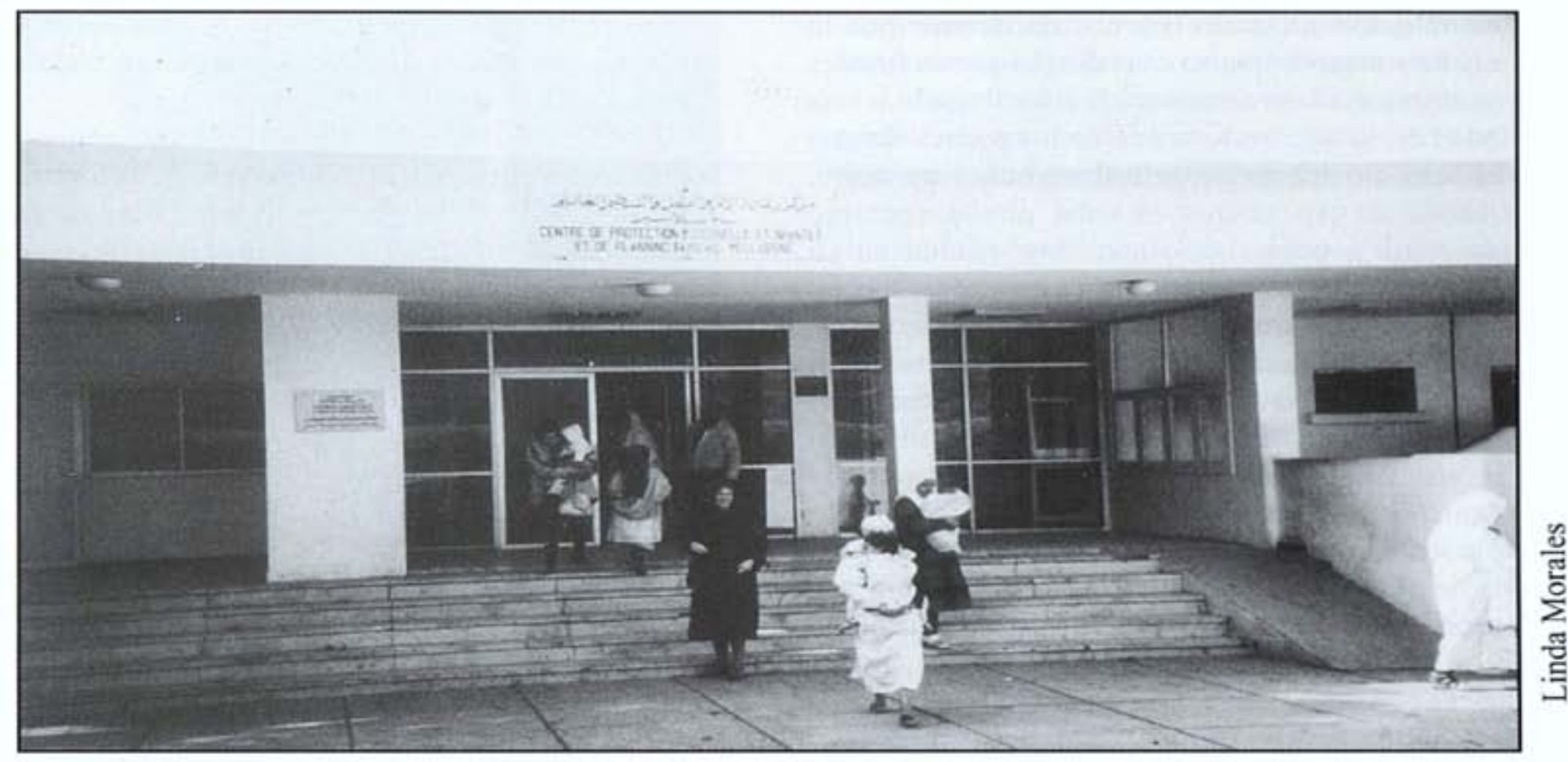

preocupación a veces más importante para ella que sus propias necesidades.

Una vez que se aseguró el apoyo de los jefes de departamento, podia iniciarse la ejecución. Fatma Gargouri y los médicos Rekik se convirtieron en un equipo de tres y empezaron a trabajar para establecer un servicio en la Maternidad que integrara la atención de parto y post-parto para la madre, incluyendo planificación familiar y atención para el bebé. A principios de 1983, se estableció la "consulta del cuarentavo día" y el programa estaba en pleno funcionamiento. En ese año, 60 por ciento de las mujeres que dieron a luz en la Maternidad regresaron a su visita post-parto; para 1987, el porcentaje había aumentado a 83 .

\section{El Significado del Cuarentavo Día}

En la mayoria de culturas musulmanas, un descanso de 40 dias después del parto se considera esencial para la recuperación de la madre y el desarrollo del bebé. Durante este periodo se protege a la madre con especial cuidado. No sale de su casa y se le libera de todas las responsabilidades del hogar, excepto la de atender a su recién nacido. Está rodeada por su familia que la atiende preparándole tés de hierbas, para ayudarla a dormir, y platillos especiales con alto contenido de hierro, glucosa y proteínas para ayudarla a recuperar sus fuerzas. Caldos con huevos ahogados, y cereales con pasas, huevos, semillas de alcaravea y algarrobo; alubias e higos secos son sólo algunos ejemplos del tipo de platillos que están tradicionalmente reservados para las mujeres después del parto. La nueva madre no debe bañarse durante este periodo, tomando sólo baños de esponja, y tampoco se le permite tener relaciones sexuales.

El cuarentavo día marca el fin de este periodo de convalecencia post-parto. Entonces, de acuerdo con la tradición, la madre puede retomar sus responsabilidades hogareñas y aparecer en público. Su primera salida de la casa es generalmente para ir al hamman o baño público. Sólo después de este ritual de limpieza puede reanudar las relaciones sexuales. Para el bebé, el cuarentavo dia representa el inicio de una nueva etapa de desarrollo. Ahora el bebé ha 
establecido un ciclo diurno, de dormir por la noche y estar despierto en el día (lo que en francés se llama rythme nictemeral) y ha llegado a una edad en la que los temores de los padres de que el bebé no sobreviva se reducen enormemente. Ahora se espera que el bebé pueda sentarse derecho $\mathrm{y}$, para simbolizar este avance en su desarrollo, se le hace una silla especial para bebé llamada "bebé-relax" (ver foto abajo).

Tradicionalmente, se lleva a cabo también una celebración el cuarentavo día, marcando el final de la convalecencia de la madre y el inicio de una rutina normal para ambos. Se reúnen la familia y los amigos, y disfrutan todos de pastelillos y dulces hechos especialmente para la ocasión. El bebé es colocado por primera vez en el "bebé-relax" y presentado a todos los niños y niñas que vienen a comer los dulces, frutas secas y nueces, y a darle la bienvenida a su nuevo hermano o amigo.

Actualmente, el grado al que se siguen estas tradiciones en Tunicia varía por región y por familia. Las prácticas van desde un estricto apego a las prohibiciones, principalmente en las regiones rurales del pais, hasta un minimo cumplimiento entre algunos habitantes urbanos.
Pero, aparte de las prácticas en el post-parto, el cuarentavo día se sigue celebrando en todo el pais.

Al unir la visita de seguimiento con este dia tan significativo, el Centro de Sfax ha logrado incorporar la visita post-parto a los ritos de ese dia. (Dado su significado cultural, la fecha es recordada fácilmente). La mayoria de las mujeres regresan exactamente 40 dias después del parto; a aquéllas para las que el cuarentavo día cae en domingo se les pide que acudan el lunes siguiente).

\section{El Momento del Parto}

Desde el día del parto, se enfatiza la conexión entre la salud del bebé y la de la madre. Inmediatamente después de dar a luz, toda mujer que lo hace en la Maternidad es examinada por un ginecólogo y visitada por un pediatra que examina al bebé junto a la cama de la madre. El pediatra anima a la madre a amamantar a su bebé y le informa de la consulta del cuarentavo día, mientras le describe los beneficios de la visita para la salud de ambos. Para la madre, el personal hace énfasis en:

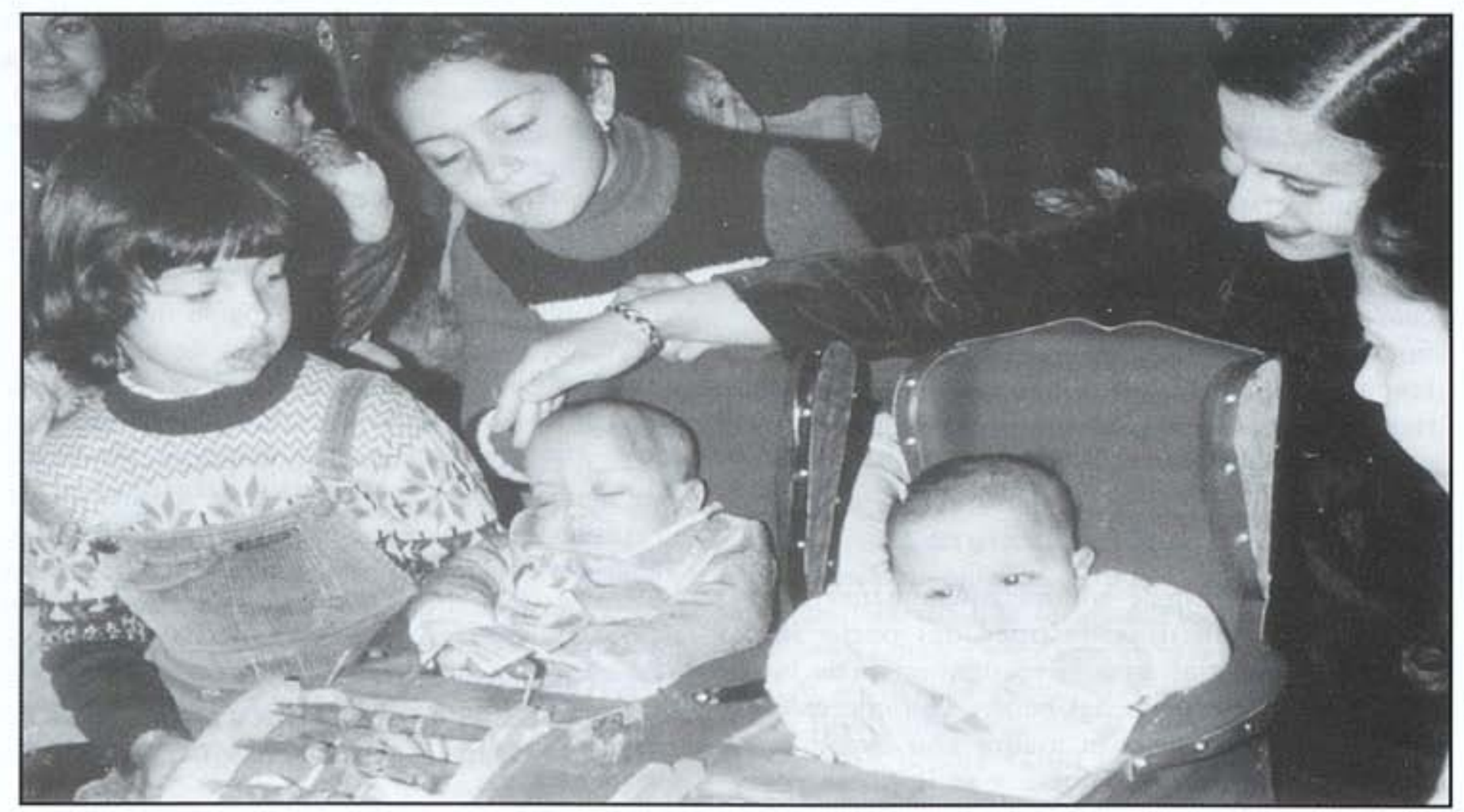




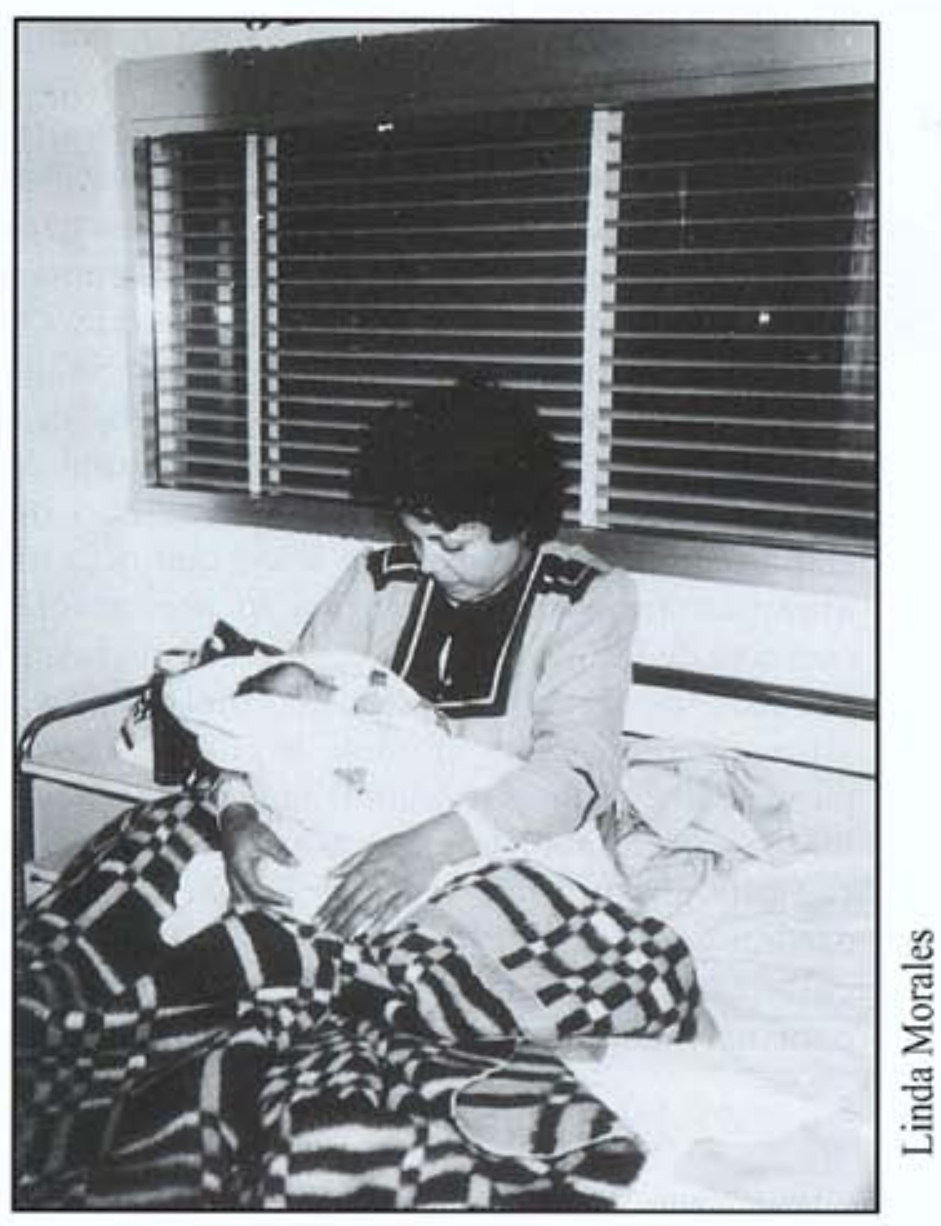

- la importancia de asegurarse que se ha recuperado bien del parto,

- la necesidad de que ella recupere sus fuerzas y su estado nutricional,

- el valor de la lactancia y cómo evitar dificultades, y

el papel de la anticoncepción como un medio para espaciar los embarazos.

Se revisa al bebé para detectar posibles anomalias y defectos congénitos que podrían no haber sido detectados durante el parto.

La mujer es también visitada por una trabajadora social quien repite lo que ha dicho el pediatra y cubre, a mayor profundidad, los temas de lactancia y la importancia de la anticoncepción. La trabajadora social le da a la mujer una tarjeta de citas, invitándola a regresar al centro en 40 dias, y subraya los tres propósitos de la visita: 1) asegurarse de su propia buena salud; 2) revisar la salud de su bebé, y 3 ) ayudarla a elegir un método de planificación familiar, si desea uno. (La tarjeta de citas contiene el número del historial médico de la mujer como guía para localizar su expediente en próximas visitas.)

La consulta del cuarentavo día se promueve también a través del uso de cassettes de audio que se tocan rutinariamente en las salas de maternidad. Estas cintas, especialmente diseñadas, contienen diez minutos de música popular tradicional y ocho minutos de mensajes sobre la importancia de la lactancia, prácticas de cuidados básicos del bebé, e información sobre la visita del cuarentavo día. La música de fondo consiste en canciones sobre el nacimiento incluyendo el grito tradicional, el you-you que hacen las parteras durante el parto en casa. Debido a que el marco del hospital priva a las mujeres de esta expresión espontánea de alegria y alivio al dar a luz, estos sonidos de apoyo colectivo se han incorporado a la cinta.

Intercalados entre las canciones hay mensajes de felicitación y consejos sobre lactancia materna, higiene de la madre y el bebé, necesidades nutricionales de la madre lactante, y la conveniencia de espaciar un próximo embarazo para asegurar la salud de la madre y el bebé. Se describen después los métodos anticonceptivos disponibles, seguidos de una invitación a regresar 40 dias después para una revisión.

El personal del hospital relata que los cassettes son muy populares y que las mujeres a menudo piden que las cintas se vuelvan a tocar una y otra vez. Muchas mujeres dicen que disfrutan de la música y quisieran que hubiera más cintas.

\section{La Consulta del Cuarentavo Día}

El cuarentavo día, la nueva madre regresa al Centro y acude a la sección especial designada para la consulta. El espacio ha sido acondicionado para proporcionar atención pediátrica en el mismo piso, y en conjunto con los servicios ginecológicos y de planificación familiar. La unidad madre-bebé, la couple mere-enfant, es atendida por un pediatra y una partera consecutivamente.

El valor que se le da a la cercania entre madre y bebé se observa en la cuna proporcionada en la sala de revisión de la madre. Manteniendo al bebé junto a ella durante la consulta, la madre se siente más segura, y no experimenta la ansiedad que sienten muchas mujeres cuando no 
saben dónde y cómo están sus bebés. Muchas mujeres mencionan este detalle, aparentemente pequeño, como una de las atracciones del servicio. Lo comparan con otros hospitales, con laberintos de largos corredores que les parecen imponentes y atemorizantes.

El primero de la couple mere-enfant en ser atendido es el bebé quien recibe una revisión completa de un pediatra. Una prueba que se realiza regularmente es un examen de oído. Este servicio se proporciona en coordinación con la Asociación de Sordomudos cuya casa matriz se encuentra en Sfax. (Se solicitó a la Asociación participar debido a la relativamente alta prevalencia de problemas congénitos de oído en la región, uno de varios problemas atribuidos a la alta incidencia de matrimonios entre familiares. La población de Sfax es particularmente conservadora y tiende a tratar de retener las herencias dentro de las familias, siendo éstas muy cerradas, con muy poco contacto con extraños).
Durante el examen médico, se discute la protección vital que proporcionan las vacunas, asi como las visitas subsecuentes y su fecha. Se canaliza después al bebé para que reciba el resto de las vacunas. (El bebé recibe la vacuna triple al nacer, pero no recibe otra vacuna el cuarentavo día porque la fecha de la visita no coincide con el programa prescrito por el Ministerio de Salud). A las madres también se les motiva para que sigan amamantando a sus bebés. Se discuten las técnicas de lactancia con aquellas madres que están teniendo problemas, y a las que no están amamantando se les explica la preparación correcta de la fórmula láctea. Se recomienda un proceso de destete paulatino, incluyendo la alimentación mixta. Durante la consulta con la partera, se discute la nutrición de la propia madre. Dichos populares tales como "Un árbol bien regado da buenos frutos" o "Alimenta el estómago y crecerá el ojo" se utilizan para enfatizar la importancia de una buena nutrición para una madre lactante. Se resalta la importancia

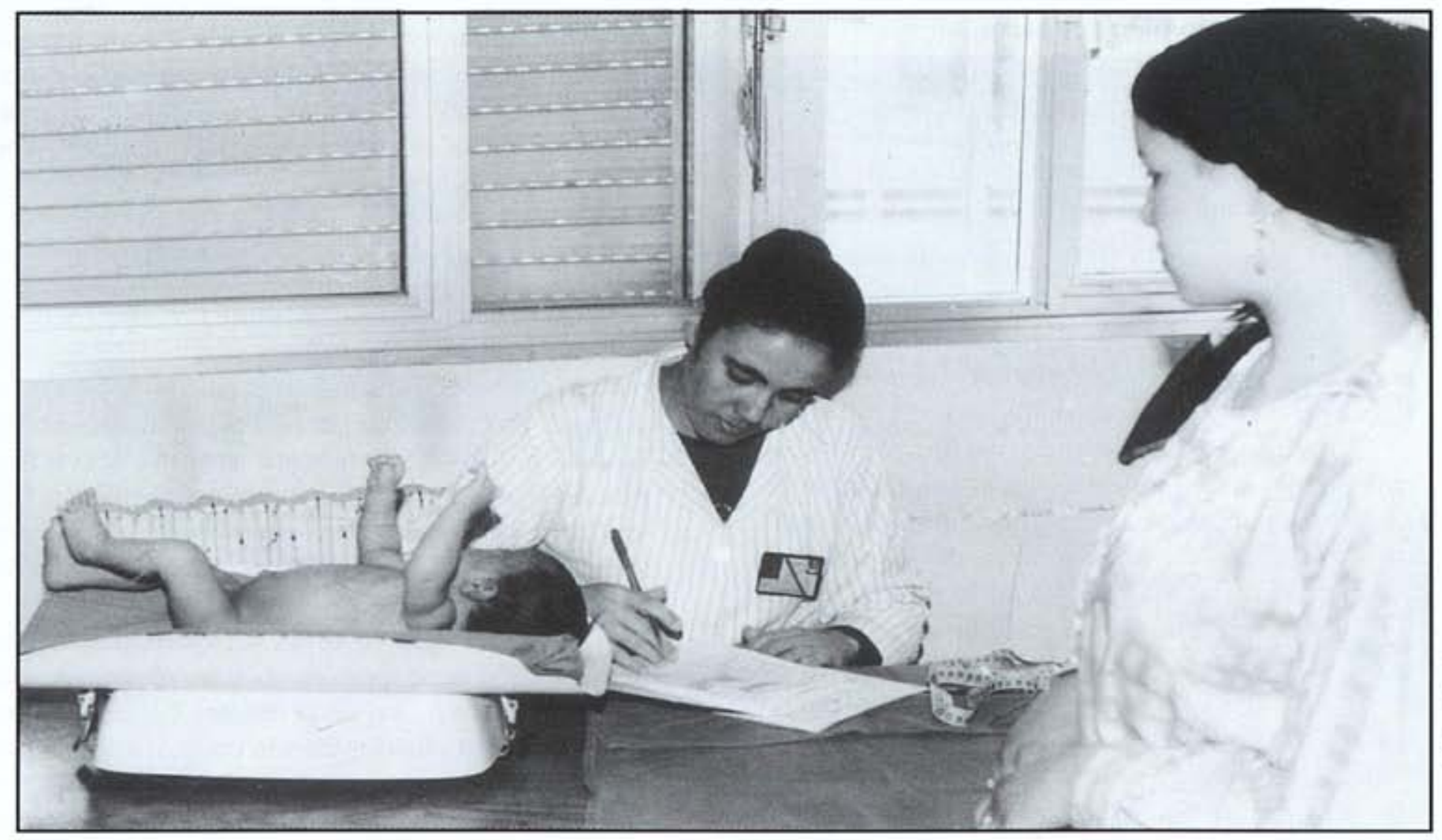




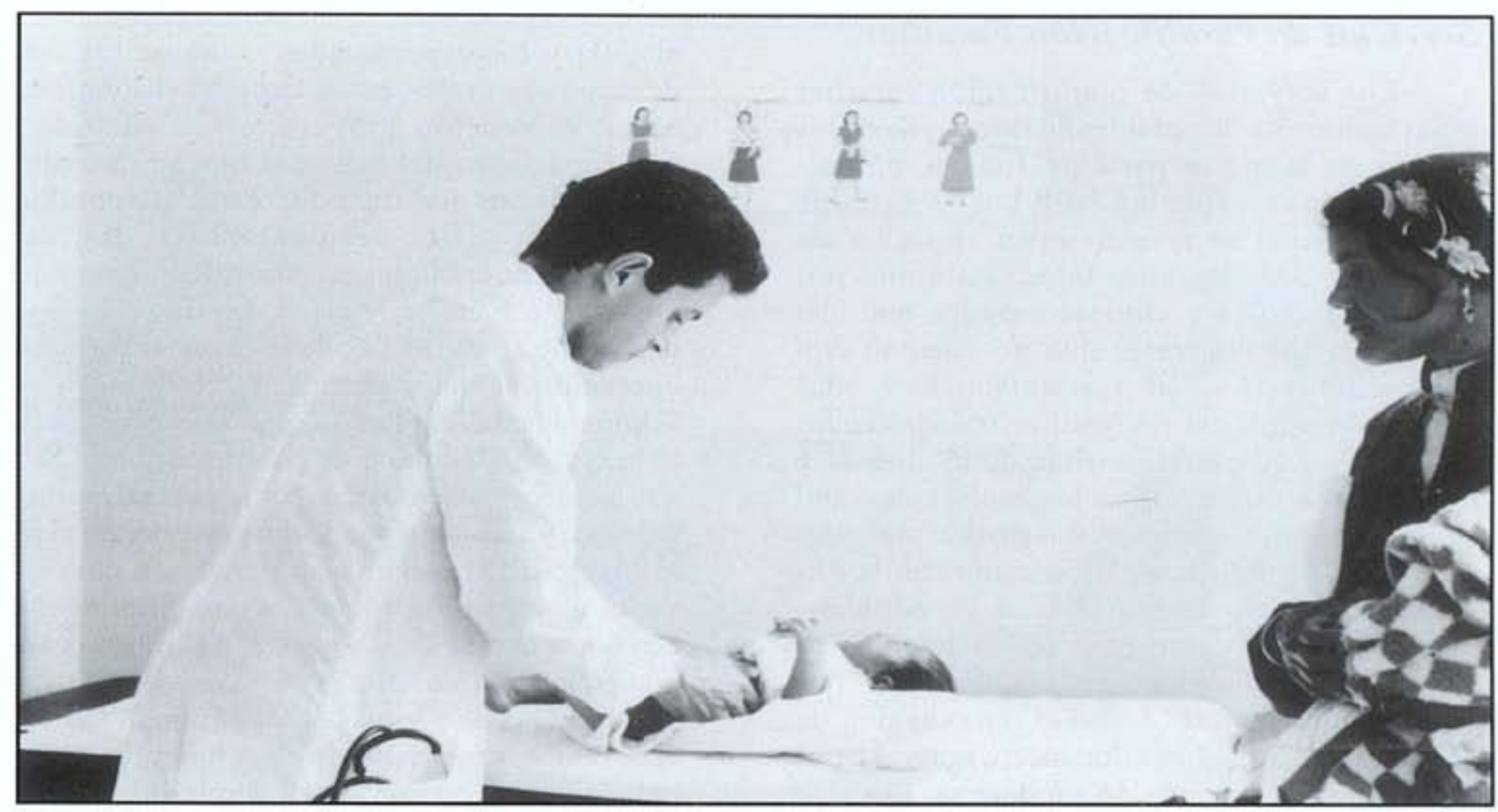

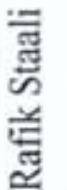

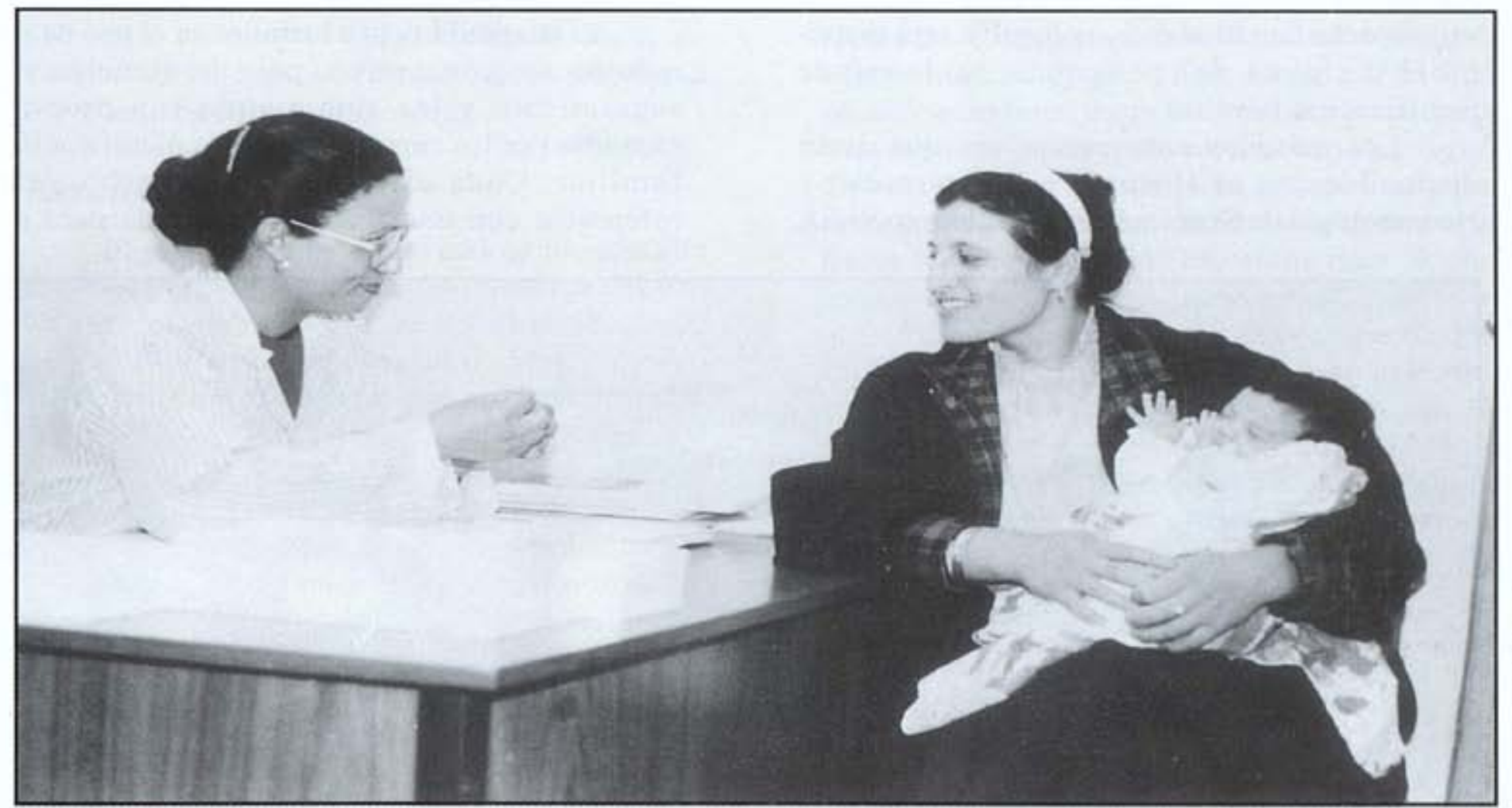

del hierro en la dieta de la madre, y se recomiendan platillos tradicionales que tienen un alto contenido de hierro.

Los servicios para la madre incluyen un examen ginecológico y la discusión de cualquier problema ginecológico que ella pudiera tener. El espaciamento de los embarazos se menciona en este momento como un importante medio para recuperar la buena salud de la madre, y para el desarrollo mental y físico del bebé. 


\section{Servicios de Planificación Familiar}

Los servicios de planificación familiar están fácilmente disponibles en la mayoria de los lugares en la mayor parte de Tunicia, proporcionados sin costo por la ONFP. Los servicios de anticoncepción se proporcionan en todos los centros de salud y hospitales, así como por unidades móviles y clínicas móviles que dan servicio a zonas rurales que no cuentan con instalaciones de salud. Las animatrices, educadoras de planificación familiar, trabajan en las comunidades haciendo visitas domiciliarias y manteniendo informados a los centros de salud sobre cualquier mujer que necesite atención especial o seguimiento. De acuerdo con la Encuesta Tunecina de Prevalencia de Anticonceptivos de 1983, realizada por el Institute of Resource Development/Westinghouse, 42 por ciento de las mujeres en edad reproductiva de Tunicia practicaban la anticoncepción y 34 por ciento usaban un método moderno. Los dos métodos más usados en 1983 fueron el DIU y la salpingoclasia. El aborto es legal y está disponible a través del programa nacional de planificación familiar.

Los métodos anticonceptivos que están disponibles en el Hospital de Maternidad y Neonatologia de Sfax incluyen la salpingoclasia, el DIU y los espermicidas. Aunque los anticonceptivos orales están también disponibles, éstos se recetan muy rara vez (debido a preocupaciones del personal que se describen abajo). Todos los métodos están disponibles durante la visita del cuarentavo dia, con excepción de la salpingoclasia. A las mujeres que eligen este método, y están dispuestas a pasar una noche en el Centro, se les programa para la operación al día siguiente. (Debido a que la salpingoclasia requiere de anestesia general, se requiere que las mujeres pasen ahí la noche y que ayunen). Sin embargo, por lo general las citas se hacen ya sea para una fecha posterior de visita al Centro de Sfax para ser operadas, o para una visita al centro de planificación familiar más cercano a la casa de la mujer. En el último caso, una educadora en salud, empleada de la ONFP, informa al centro local del interés de la mujer y ésta recibe una visita de seguimiento de una trabajadora de campo, en su domicilio, antes de su cita para la operación.

El hospital inicia a la mujer en el uso de un método anticonceptivo, pero la atención de seguimiento y los suministros son proporcionados por los centros locales de planificación familiar. Cada cliente recibe una hoja de referencia con una fecha aproximada para su

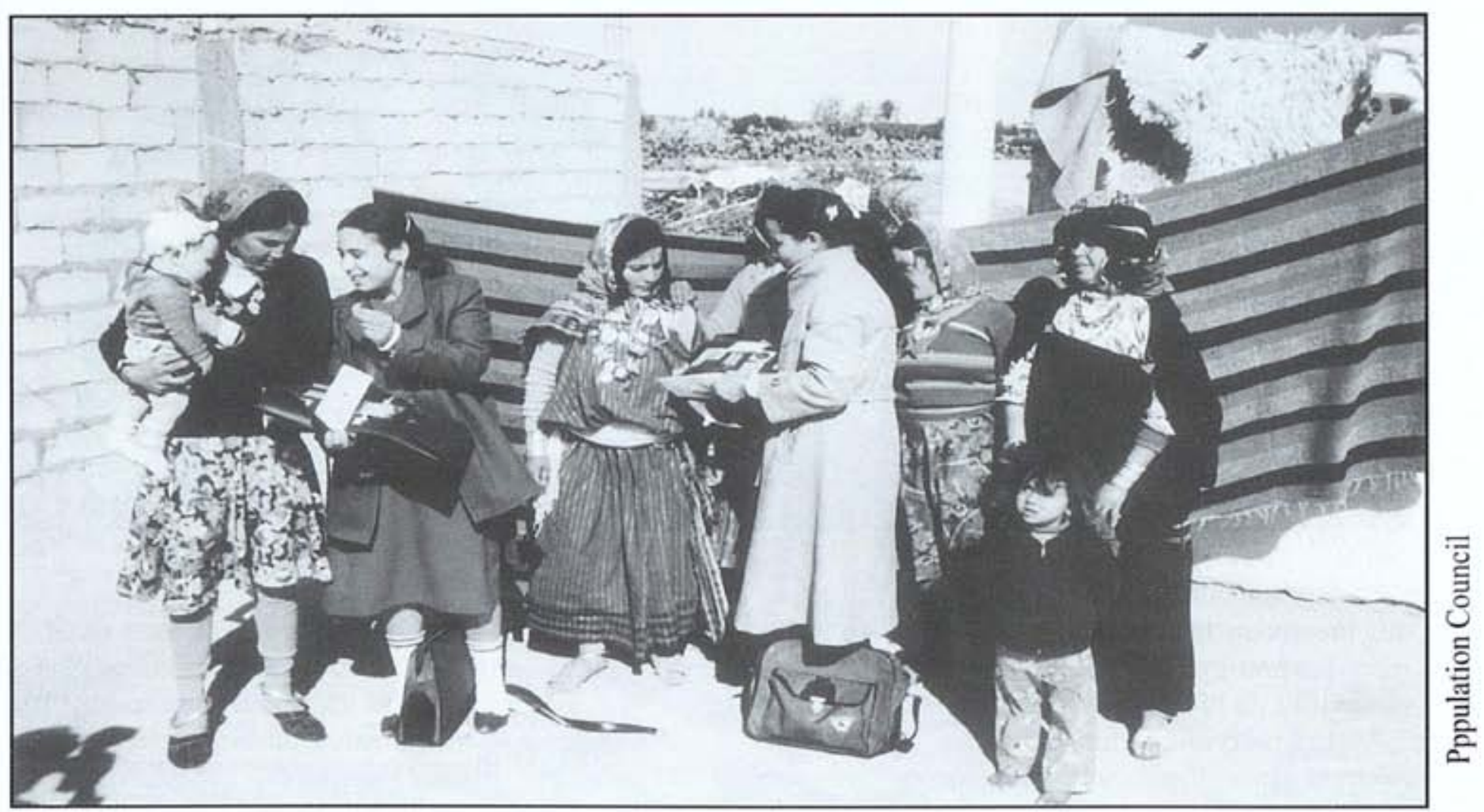




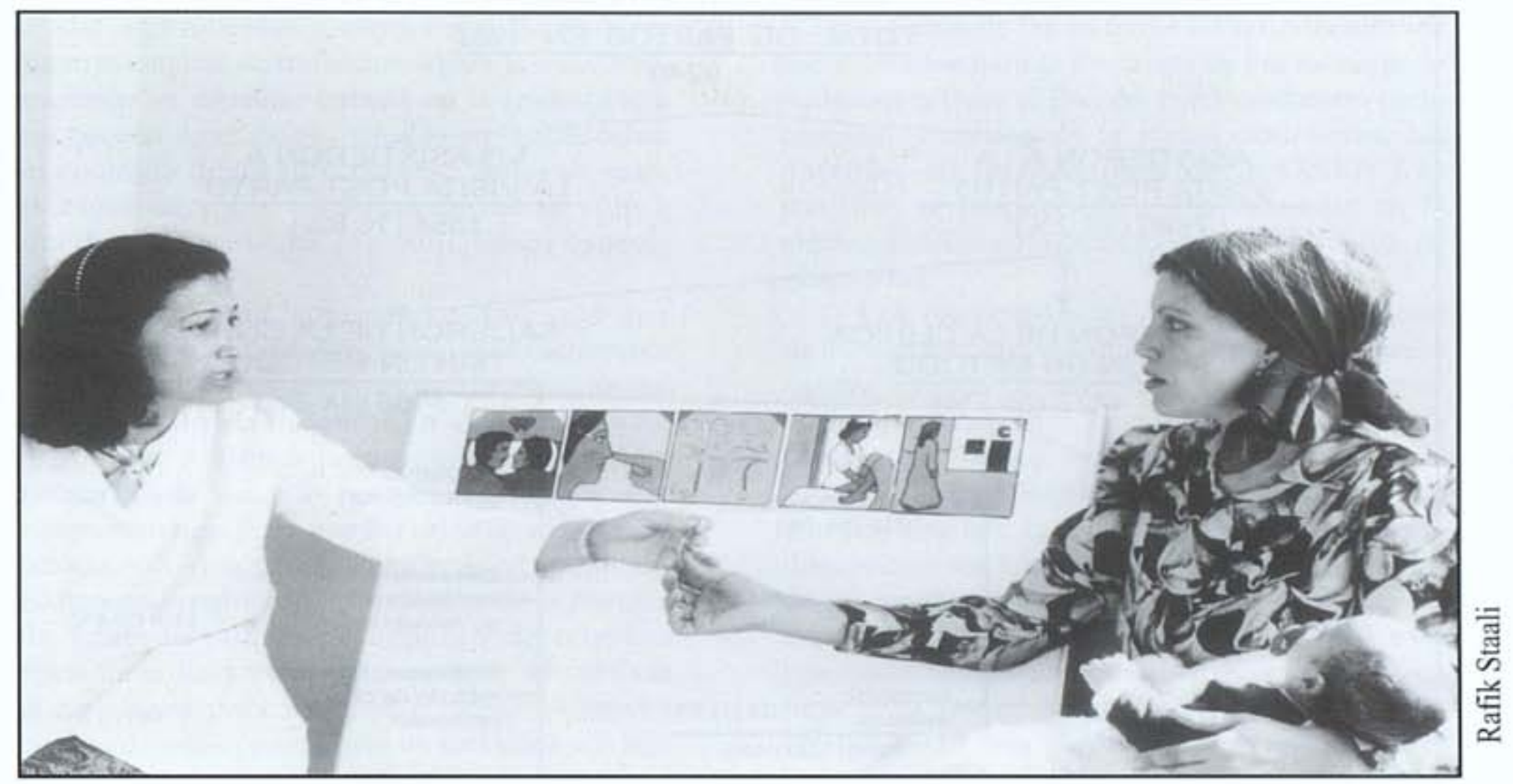

próxima visita. Al final de cada mes, se distribuyen las copias de estas hojas de referencia a los centros correspondientes.

\section{Resultados}

El programa post-parto ha logrado una alta tasa de regresos y promoción oportuna del uso de anticonceptivos. De las 9,240 mujeres que dieron a luz en la Maternidad de Sfax en 1987, el 83.2 por ciento $(7,686)$ regresaron al centro para su revisión post-parto. Esto es un aumento de 73.3 por ciento en 1986 y de 60 por ciento en 1983. De las 7,686 mujeres que regresaron para la visita post-parto en 1987 , el 55.6 por ciento $(4,277)$ aceptaron un método de planificación familiar durante esa visita, y a todas se les informó sobre los métodos disponibles y los servicios de planificación familiar más cercanos a su domicilio.

\section{Mejorando la Calidad de los Servicios}

Empeñado en mejorar el programa, en 1988 el personal empezó a buscar formas de aumentar el impacto y la cobertura. Al principio, se hizo énfasis en el establecimiento de un sistema para localizar y entrevistar a las mujeres que no habian regresado a la visita del cuarentavo día ( 16.8 por ciento de las mujeres que habian dado a luz en la Maternidad en 1987). Esta tarea, por si sola, resultó ser tediosa; después el contactar realmente a las mujeres en sus casas sería tardado y costoso. Como resultado, y dada la ya existente alta tasa de regresos, el personal decidió concentrarse en hacer los servicios más efectivos para la gran mayoría de las mujeres que si los utilizan.

La efectividad de la visita post-parto como táctica para promocionar los métodos anticonceptivos entre las mujeres era de particular interés. Con base en las estadisticas de servicio de 1987, las usuarias fueron separadas en dos grupos, aquéllas que habian aceptado un método durante la visita del cuarentavo dia y las que no. Estos dos grupos fueron divididos según el método que habian escogido o la razón por la que no recibieron un método (véase figura de la página $\mathrm{XX}$ ).

De este análisis surgió un buen número de observaciones útiles. La primera fue que aproximadamente la mitad (44.3 por ciento) de las mujeres salian de la clínica sin un método. La pregunta obvia era "¿Por qué?" Las razones podrian clasificarse en tres categorias: 1) mujeres a quienes se les habian diagnosticado problemas ginecológicos (considerados por el programa como contraindicaciones para la anticoncepción), 


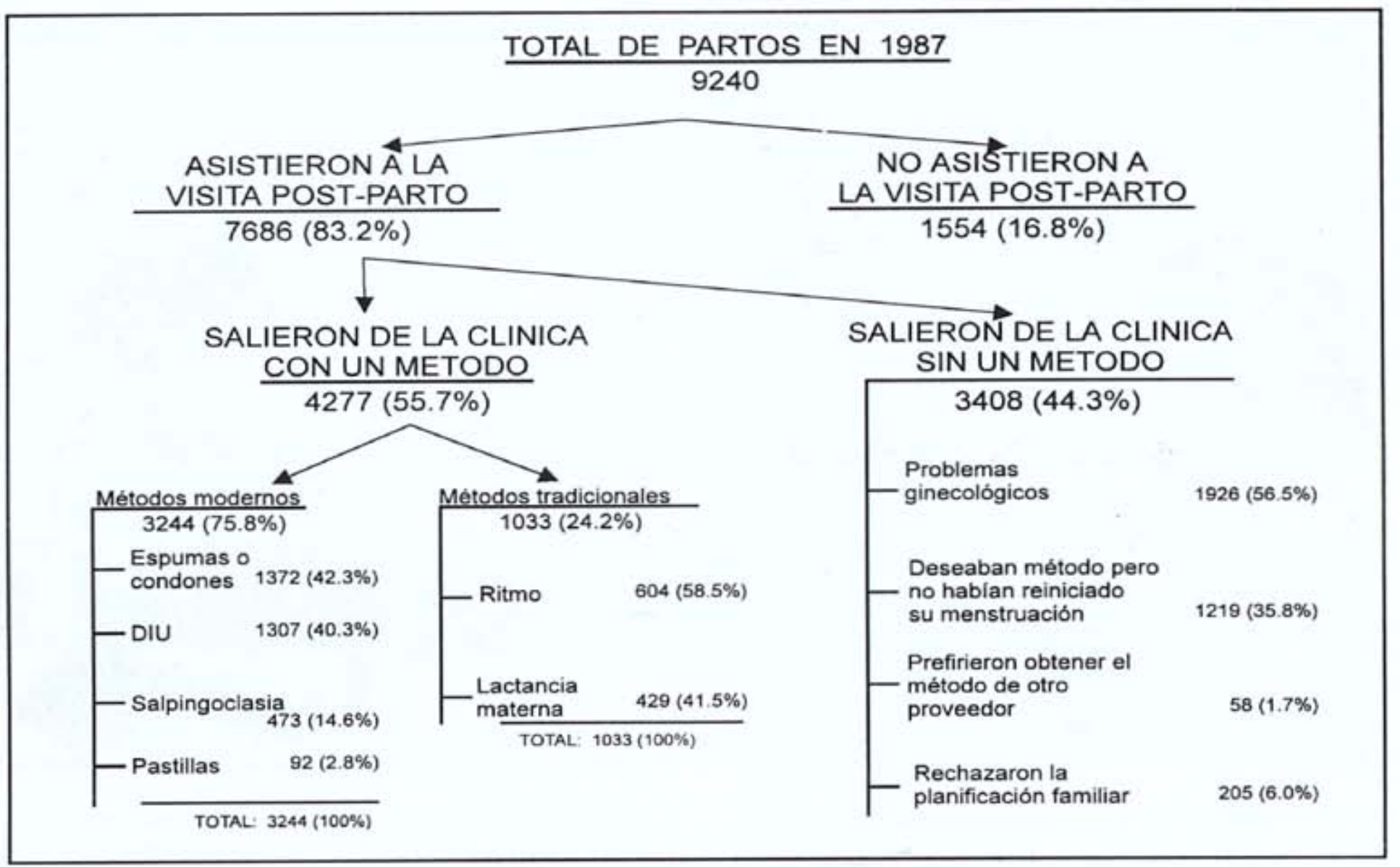

46.3 por ciento; 2 ) mujeres que habian expresado interés en practicar la anticoncepción pero, sin embargo, salieron sin un método, 48.8 por ciento, y 3 ) aquéllas que no estaban interesadas en practicar la anticoncepción, 4.9 por ciento.

De hecho, sólo un pequeño número, 205 mujeres, rechazaron un método (igual a 2.7 por ciento de todas las mujeres que acudieron a la clinica a consulta y 6 por ciento de las que se fueron sin un método). Esto implicaba que la aceptabilidad del espaciamiento de los nacimientos era bastante alta entre esta población. Pero si el rechazo a la práctica de la anticoncepción era tan bajo ¿cómo se explican las 3,204 mujeres que salieron del centro $\sin$ un método? Las respuestas a esta pregunta proporcionaron algunas recomendaciones concretas sobre las formas de aumentar el interés de las mujeres en la anticoncepción post-parto.

Las contraindicaciones ginecológicas fueron la razón por la que no recibieron un método anticonceptivo la gran mayoría de las mujeres que salieron sin él. Estos problemas incluían flujo generalizado (en 72.6 por ciento de los casos), inflamación cervical ( 25 por ciento), y problemas fisicos como útero anormal (2.4 por ciento).

Debido a que el DIU o la salpingoclasia están contraindicados en mujeres que presentan síntomas de infección, y puesto que el centro actualmente no cuenta con equipo de laboratorio para examinar infecciones del tracto reproductivo, ni medicamentos para su tratamiento, el protocolo en la Maternidad de Sfax es canalizar a tratamiento a todas las mujeres que solicitan un método de planificación familiar pero que se sospecha que tengan una infección vaginal. Estas mujeres reciben generalmente una receta para antibióticos y se les indica que acudan a la clínica de planificación familiar más cercana para un examen de seguimiento y un método, dos semanas más tarde. Aquéllas que prefieren regresar al centro para seguimiento reciben una nota que les da prioridad para ser atendidas de inmediato, cuando regresen.

En vista de que casi la mitad de las usuarias potenciales de planificación familiar volvían a casa sin un método, se vio claramente la necesidad de revaluar estos procedimientos. Se hicieron dos sugerencias inmediatas. La primera 
fue dar espermicidas o condones a las mujeres mientras estaban en tratamiento para la infección, poniendo un especial énfasis en la importancia que pueden tener estos métodos en la reducción del contagio de las infecciones. Antes de esto, las espumas y los condones se daban sólo a aquellas mujeres que los solicitaban especificamente.

La segunda sugerencia fue que los anticonceptivos orales estuvieran más fácilmente disponibles. Las dudas en cuanto a la prescripción de la pastilla se basaban en dos creencias: 1) que las mujeres menos educadas no se acordarian de tomar la pastilla regularmente, y en consecuencia provocarían la inefectividad del método, y 2) que debido al extenso seguimiento médico que requieren las usuarias de la pastilla (de acuerdo con la percepción de muchos prestadores de servicios tunecinos), el método no es seguro para mujeres rurales. Además, muchos de estos prestadores de servicios son aún muy cautelosos debido a las contraindicaciones de los anticonceptivos orales, tales como la hipertensión, y prefieren recetar uno de los otros métodos. Esta actitud refleja la parcialidad general de la ONFP en contra de recetar anticonceptivos orales y esto se ilustra con la baja prevalencia de uso del método en Tunicia: sólo
5.3 por ciento de las usuarias de anticonceptivos entrevistados para la Encuesta de Prevalencia de Anticonceptivos (EPA) de 1983 confiaron en la pastilla, y menos de la mitad obtuvieron las pastillas en instalaciones de la ONFP. Las pastillas se proporcionan generalmente en la clinica de Sfax sólo cuando una mujer insiste en obtenerlas.

Las inquietudes en cuanto a la seguridad de los anticonceptivos orales son particularmente agudas cuando se refieren a mujeres lactantes. Desafortunadamente, esta situación se acentúa por el hecho de que los anticonceptivos de dosis baja, de progestina únicamente, que son compatibles con la lactancia materna, no están disponibles en Tunicia. Por lo tanto, el Centro de Sfax no proporcionará pastillas a las mujeres lactantes por el momento. El personal está pensando ordenar anticonceptivos orales de dosis baja para poder empezar a probar su aceptabilidad. El uso adecuado, combinado con la capacitación para reconocer cuándo deben recetarse estas pastillas, sería la mejor forma de convencer al personal de su seguridad y eficacia.

La segunda razón importante por la cual las mujeres salieron de la clínica sin un método ( 35.8 por ciento) fue que todavia no habia regresado su menstruación. De acuerdo con el

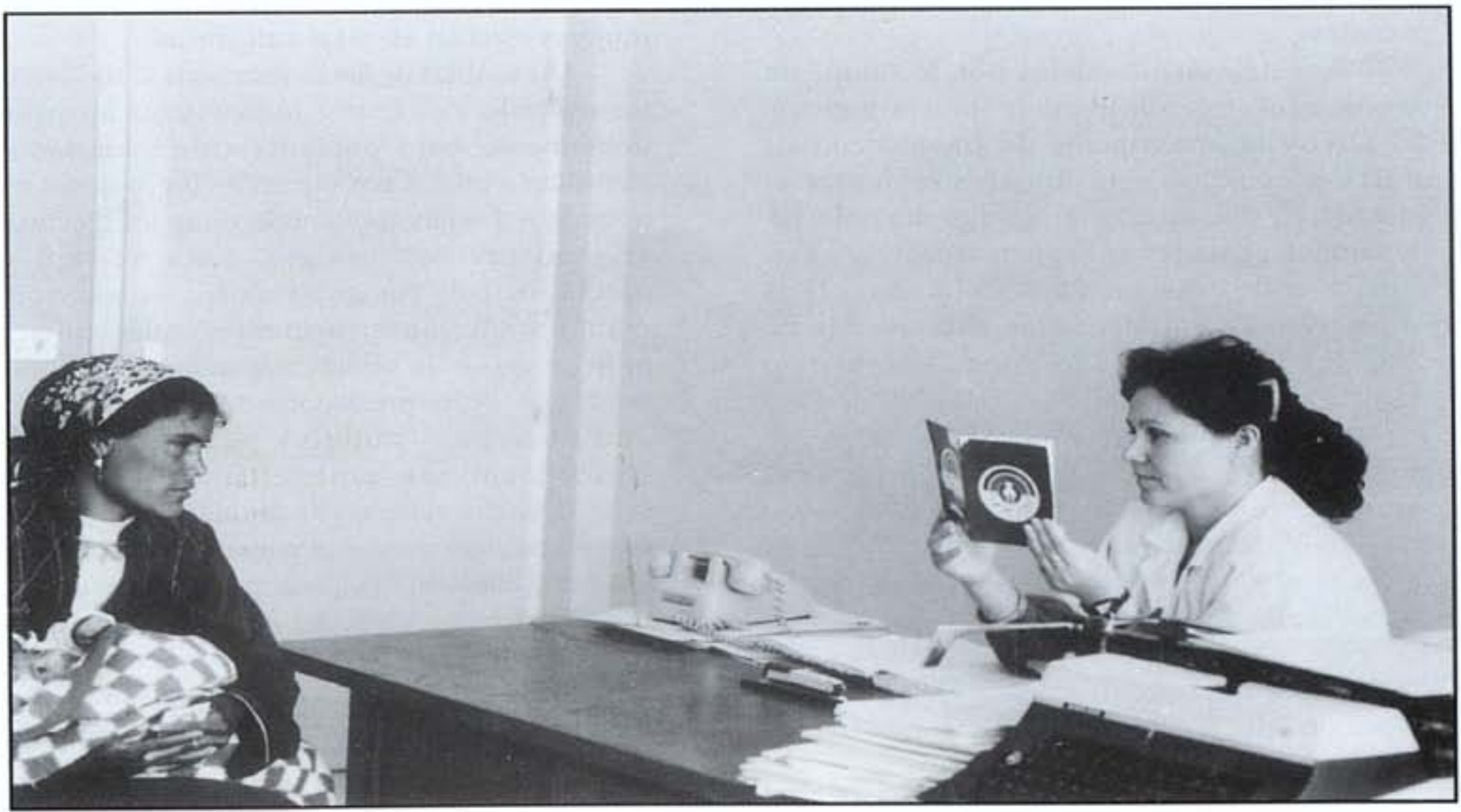


protocolo médico, los DIUs sólo pueden colocarse durante la menstruación (para facilitar la inserción y asegurar que la mujer no esté embarazada). En la pequeña medida en que están disponibles, también se proporcionan anticonceptivos orales cuando se reanuda la menstruación, indicador de que la mujer no está embarazada. Por lo tanto, a 1,219 mujeres que deseaban adoptar la anticoncepción se les dijo que necesitaban estar menstruando para poder recibir un método, y se les canalizó a la clínica de planificación familiar más cercana.

La necesidad de un protocolo tan estricto para un programa que atiende a la mujer sólo 40 días después del parto, cuando es muy improbable que esté embarazada, fue ampliamente diseutida por el personal. Mientras que una visión tan conservadora en cuanto a la seguridad de no embarazo puede ser necesaria en el contexto de un programa nacional, que da servicio a las áreas rurales remotas con equipos móviles que brindan servicios sólo en ciertos periodos, la aplicación del mismo protocolo para mujeres que acaban de dar a luz y están amamantando es inadecuado.

Una excepción de este protocolo es para mujeres que solicitan un DIU y dicen que no han reanudado las relaciones sexuales. Sin embargo, esto deja desprotegidas a las mujeres que están en mayor riesgo de un embarazo no deseado, o sean las que ya reanudaron las relaciones sexuales.

Se está considerando, por lo tanto, un cambio en el protocolo que permitiría la inserción del DIU y la prescripción de anticonceptivos orales adecuados para mujeres lactantes el cuarentavo día, se hayan o no reanudado las relaciones sexuales o la menstruación. Los beneficios de estos cambios incluirían: 1) la posibilidad de satisfacer las necesidades de anticoncepción de un número significativo de mujeres que actualmente no están recibiendo servicios; 2) la reducción del temor de un embarazo para mujeres que pueden estar en un mayor riesgo de embarazo no deseado (dado que han reiniciado relaciones sexuales), y 3) la reducción de los costos globales de la anticoncepción para la usuaria y el prestador de servicios. (En el sistema actual, las mujeres que si resultan embarazadas abortan y luego se les coloca un DIU.)
Como resultado de estas discusiones, ahora está vigente un nuevo protocolo aplicable a las mujeres que solicitan el DIU y que no han menstruado todavia. Las mujeres reciben ahora un examen pélvico y se les pide vuelvan a la clinica una semana después. Si el útero no ha crecido, descartando asi un posible embarazo, se les coloca entonces un DIU. Este procedimiento fue el compromiso al que llegaron los directores médicos, quienes sienten la necesidad de apegarse a los protocolos médicos, y demás personal que quiere reducir los obstáculos a los que se enfrentan las mujeres que quieren usar un DIU. Sin embargo, el requerimiento de que la mujer regrese una semana más tarde puede ser un inconveniente innecesario para la cliente, además de exponerla al riesgo de que se embarace durante esa semana. Se espera que, con el tiempo, y después de determinar realmente cuántas mujeres están embarazadas, se podrán realizar más cambios para proporcionar el método durante la visita del cuarentavo día.

Las otras dos razones por las que las mujeres salieron $\sin$ un método fueron porque preferían obtener sus servicios de planificación familiar de otro proveedor ( 1.7 por ciento) o porque no estaban interesadas en la planificación familiar (6.0 por ciento). Ya que el programa podia hacer poco para reducir estas cifras, el personal se alegró al descubrir que tan pocas mujeres estaban en estas categorías.

Un análisis de las mujeres que si recibieron un método confirmó también el sorprendentemente bajo porcentaje de usuarias de pastillas (a un 2.8 por ciento de las mujeres que optaron por un método moderno se les recetaron anticonceptivos orales). Esto reflejó la parcialidad de los prestadores de servicios mencionada anteriormente, más que la preferencia de la cliente, ya que las preguntas informales de los prestadores de servicios indican que muchas mujeres escogerían los anticonceptivos orales como método si estuvieran disponibles, incluyendo a las mujeres que no reciben servicios actualmente o quienes usan el ritmo o la lactancia solamente.

Esta evaluación del programa post-parto resultó ser muy útil para el personal para identificar varias formas en que pueden mejorar la calidad y el rendimiento de su programa a muy 
bajo costo adicional. El reto ahora es ejecutar las recomendaciones hechas y, subsecuentemente, evaluar su contribución a la satisfacción del cliente y el uso de los servicios.

\section{Otros Aspectos de los Servicios de Calidad}

Al personal le gustaría mejorar también otros aspectos del programa. Una preocupación es la recepción de hombres en la clinica. Actualmente no existen servicios para los esposos u otros hombres que acompañan a las mujeres y los bebés a las clínicas. Los que llegan, y parece ser un número significativo, tienden a esperar afuera del centro, conversando entre ellos.

El interés de cada uno de ellos en ser incluidos en la visita puede variar. Las siguientes son algunas respuestas que dieron los hombres cuando se les preguntó si les gustaría participar:

"Nos hacen sentir como extraños."; "Esto es cosa de mujeres y no debemos meternos."; "Se nos hace a un lado..."; "Por la forma en que se nos trata se pensaria que esto no nos concierne."; "Me gustaría escuchar lo que dice el doctor (sobre la consulta pediátrica) pero sólo se le permite entrar a mi esposa."
El personal está pensando en formas de dar la bienvenida a los hombres y de incluirlos, de alguna manera, en el servicio.

Otra meta del personal es mejorar la atmósfera del área de recepción. Actualmente es muy rigida y formal. En la entrada a la sala, hay un gran espacio abierto sin usar porque las mujeres prefieren esperar en un pequeño cuarto al fondo, que es más privado y con menos corrientes de aire (en la cultura popular, a los bebés casi no se les saca de la casa a esta edad, para protegerlos de las corrientes de aire). El resultado es que el pequeño cuarto está frecuentemente repleto de mujeres, y su tamaño y ubicación interfieren con el movimiento de la clínica. Por lo tanto, se están discutiendo varias formas de hacer la sala del frente más acogedora, incluyendo: dividir el espacio con mamparas movibles, que podrian estar hechas de telas locales de mucho colorido o cubiertas con llamativos carteles informativos; y la construcción de bancas bajas cubiertas con cojines para que se sienten las mujeres. Estas bancas son tipicas de la arquitectura tradicional tunecina y son particularmente cómodas para las mujeres mientras amamantan porque pueden

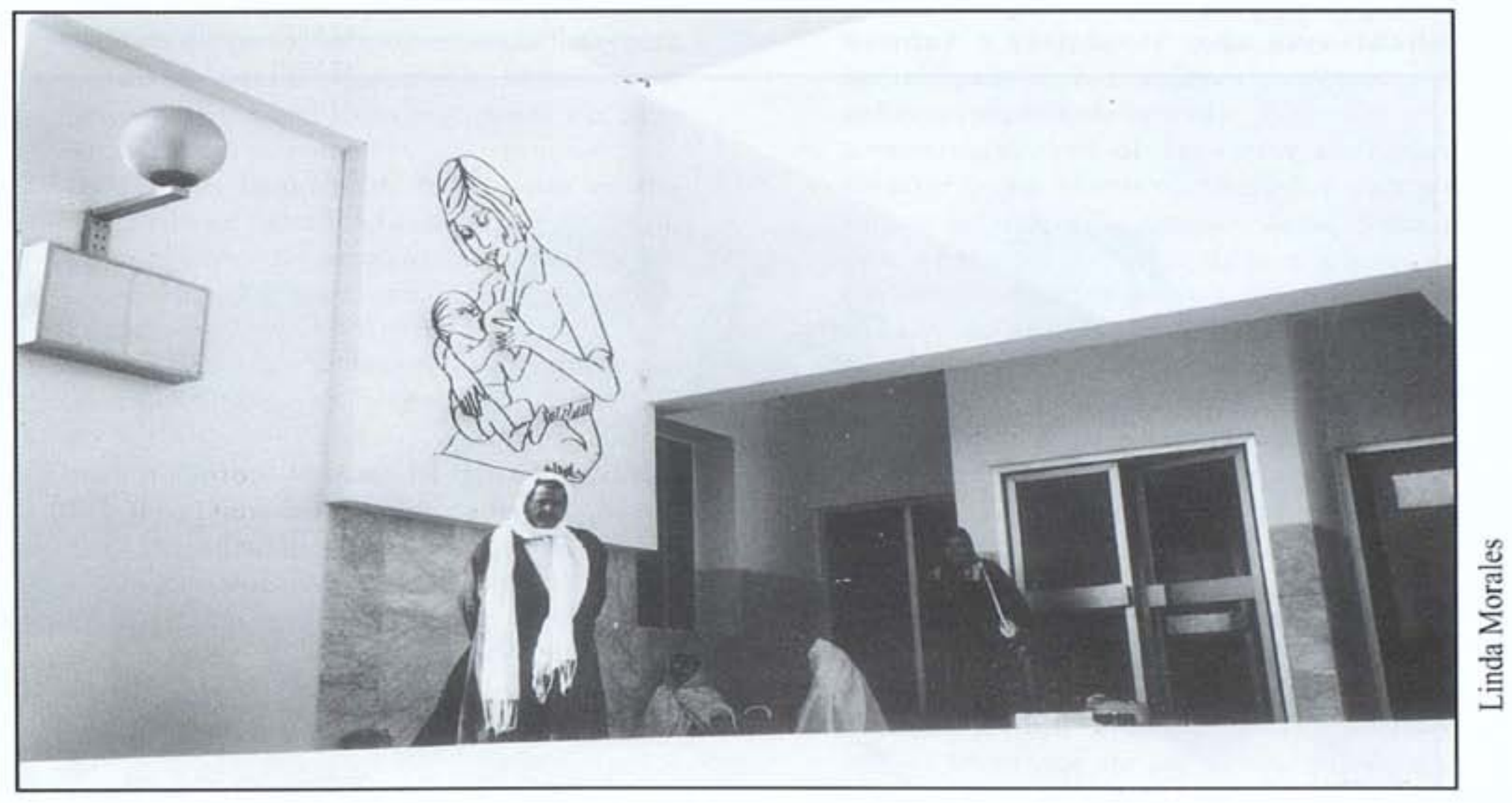


sentarse con las piernas cruzadas al frente, posición que no pueden adoptar en las angostas bancas de madera que se encuentran actualmente en la enorme sala de espera.

Finalmente, el personal quiere establecer un mejor sistema de información administrativa. En el sistema actual, cada visita que una mujer hace al hospital durante un embarazo especifico, ya sea para atención prenatal, parto, o atención post-parto, se registra en una misma gráfica, facilitando así la continuidad de atención. Sin embargo, debido a que se abre una nueva gráfica para cada embarazo, no es posible seguir fácilmente la historia de una mujer a través de los años, lo cual sería muy útil tanto para una mejor continuidad de atención como para evaluar el impacto del programa de planificación familiar y proporcionar seguimiento a las mujeres consideradas en riesgo.

Aunque los registros están diseñados para análisis por computadora (están codificados y podrían ser procesados fácilmente), a la fecha el centro no cuenta con el equipo necesario ni las habilidades analiticas para computarizar su sistema de registros. El establecimiento de semejante sistema de información administrativa computarizado es una de las mejoras que el Centro está planeando realizar.

\section{Moviéndose en Otras Direcciones}

A escala nacional, la ONFP está viendo este programa como un posible prototipo para los servicios post-parto. Además, al programa nacional de planificación familiar le gustaría descentralizar los servicios post-parto, para permitirles a las mujeres acudir a centros de salud más cercano a sus casas. Por ejemplo, cuando se descubrió que varias mujeres que no regresaban al Centro para su consulta post-parto estaban yendo a una clinica manejada por el sistema Nacional de Seguridad Social (que proporciona servicios de salud a 33,000 empleados de empresas privadas afiliadas), el personal de planifícación familiar hizo un esfuerzo para establecer un programa similar al de la Maternidad de Sfax en esta clínica. Los servicios de planificación familiar se iniciaron con personal de la ONFP, y operaban paralelamente a los servicios pediátricos; después contrataron a un ginecólogo. Como sucede con frecuencia, los lazos personales tuvieron que ver en esta innovación: la hermana de Fatma Gargouri fue nombrada directora de la clínica y los pediatras eran discípulos de Ahmed Rekik.

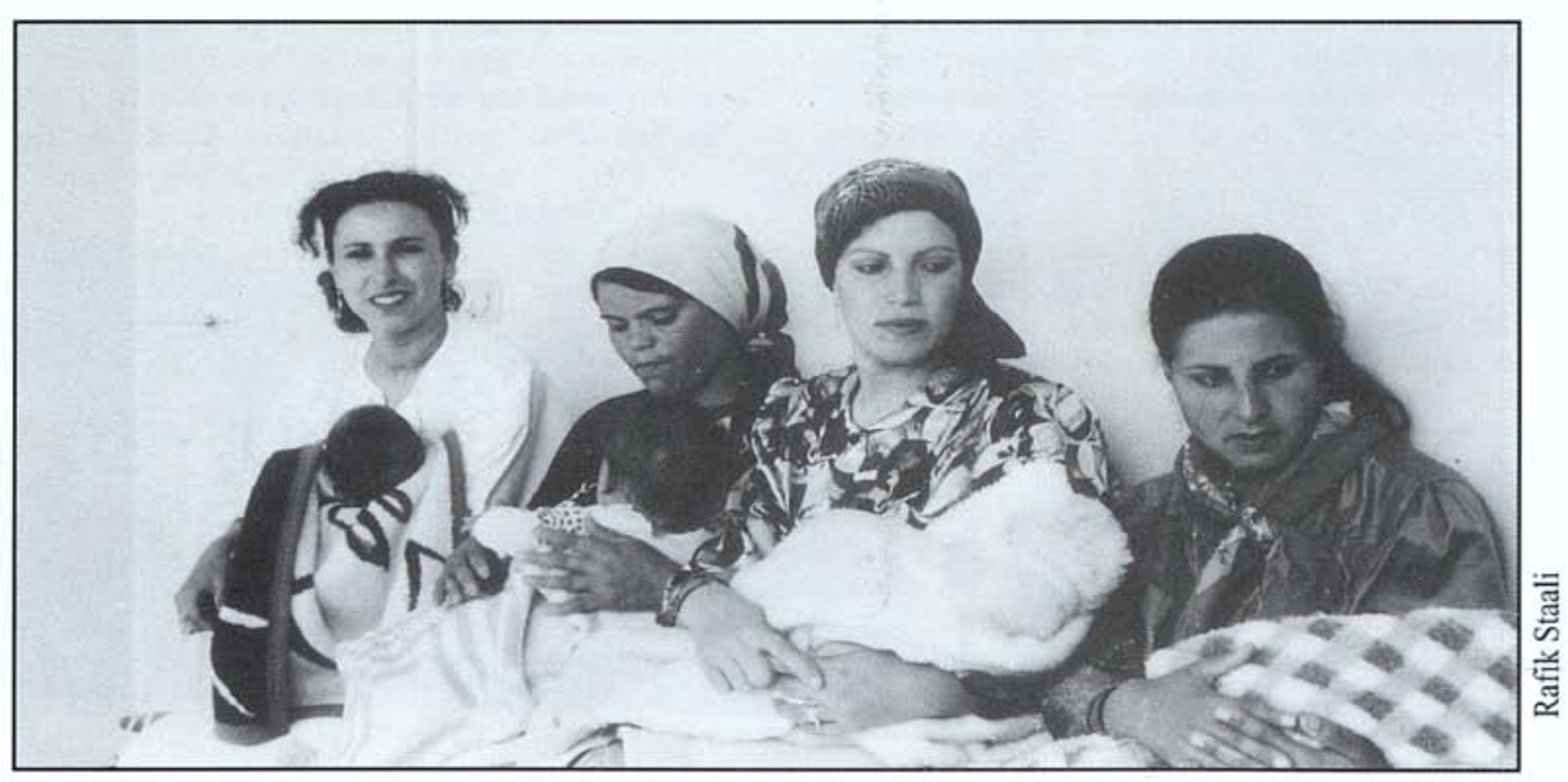




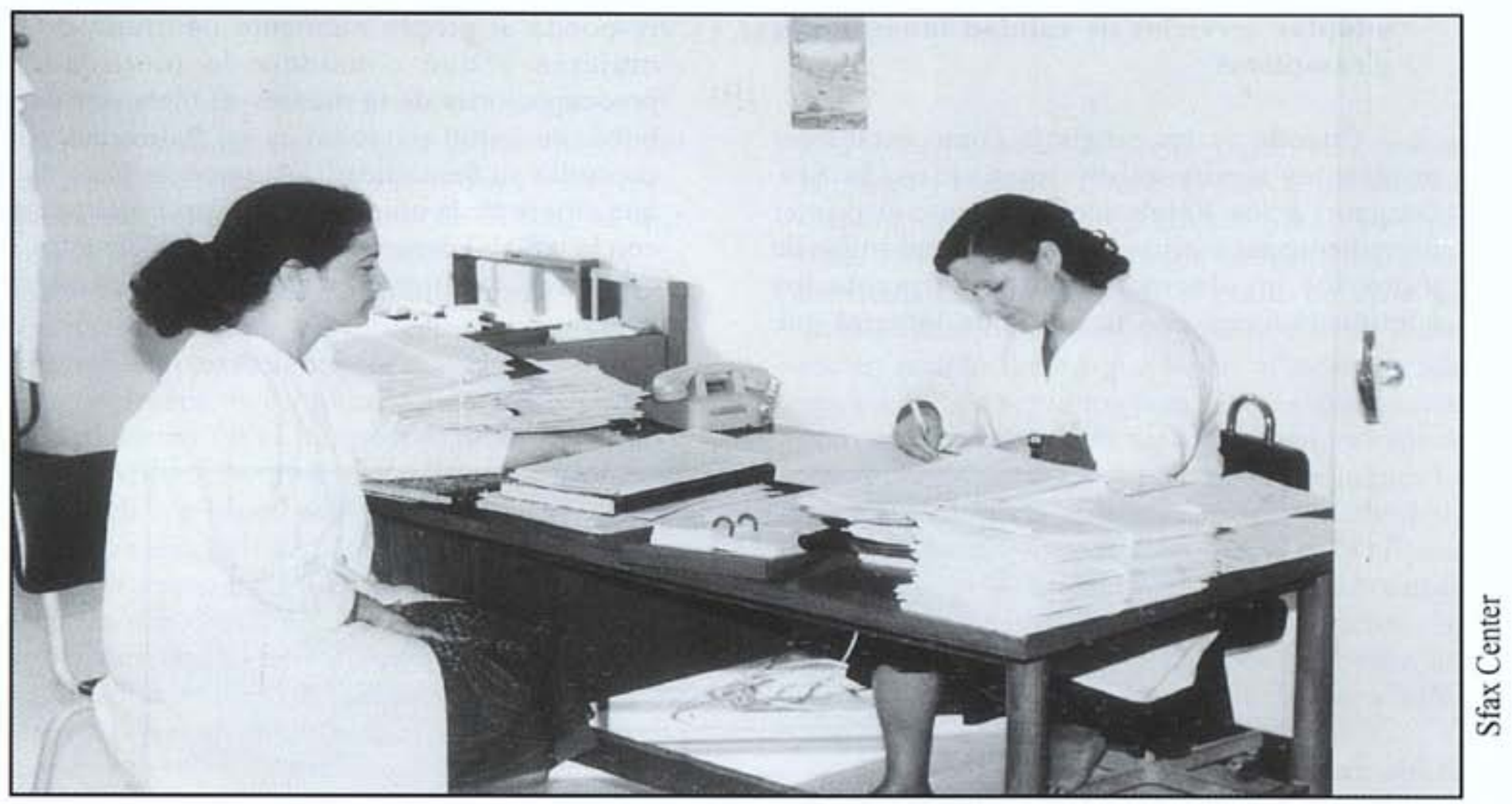

\section{Lecciones Aprendidas}

1. La prestación de servicios anticonceptivos a las mujeres en el momento adecuado es un elemento clave para el éxito de un programa de planificación familiar postparto. En Tunicia, para el cuarentavo día después del parto, las mujeres están listas para pensar en la anticoncepción; ha terminado su periodo de recuperación post-parto, y el bebé se encuentra ya estable.

2. Relacionar la fecha de la cita con un día que tiene un significado cultural fue crucial para el éxito del programa. No sólo sirve como un recordatorio, sino también corresponde al propio sentido de temporalidad de la mujer en cuanto a sus necesidades de salud y las del bebé.

3. El enfoque del programa sobre la couple mere-enfant tiene múltiples beneficios, incluyendo: a) motivación de la madre para regresar a consulta de seguimiento para ambos, ella y su bebé; b) mejora de la atención post-parto e infantil, y c) aumento del espaciamiento de los embarazos y el uso de anticonceptivos. En un principio, el creciente número de mujeres que acudían al programa indicaba al personal el nivel de la demanda insatisfecha de servicios integrados de atención post-parto, salud infantil y anticoncepción.

4. Es necesario aumentar la oferta de métodos disponibles para mujeres lactantes en el periodo post-parto; esto podría ayudar a satisfacer más necesidades individuales de las mujeres y aumentar la cobertura anticonceptiva.

5. Los prestadores de servicios necesitan tiempo para sentirse cómodos con un nuevo servicio. En muchos casos, tendrán que vencerse algunos sentimientos de territorialidad sobre quién es responsable de cada tarea. En el caso de la Maternidad de Sfax, si no hubiera sido por el compromiso de los jefes de ambos departamentos de ginecologia y de pediatría, el programa probablemente no habría podido vencer muchos de estos obstáculos. Pero ese compromiso, junto con el éxito aparente del programa y su popularidad entre los clientes, ha hecho mucho para motivar al personal.

6. El compromiso con el bienestar de las mujeres y su derecho a espaciar los nacimientos, combinado con un compromiso con el bienestar de los bebés, puede aumentar la motivación del personal para 
adoptar servicios de calidad innovadores y completos.

Cuando se les pregunta cómo establecer programas similares en otros sitios, la Sra. Gargouri y los Rekik aconsejan que el primer ingrediente necesario es el firme compromiso de todos los involucrados, particularmente los administradores, con un enfoque integral que responda al propio momento oportuno de las mujeres y que considere la totalidad de preocupaciones de la madre: el bienestar de su bebé, su salud personal, y su habilidad para controlar su fecundidad. Aunque no hace daño que el jefe de la unidad de pediatría esté casado con la jefa del departamento de ginecobstetricia, esto no es, insistieron en agregar, absolutamente necesario.

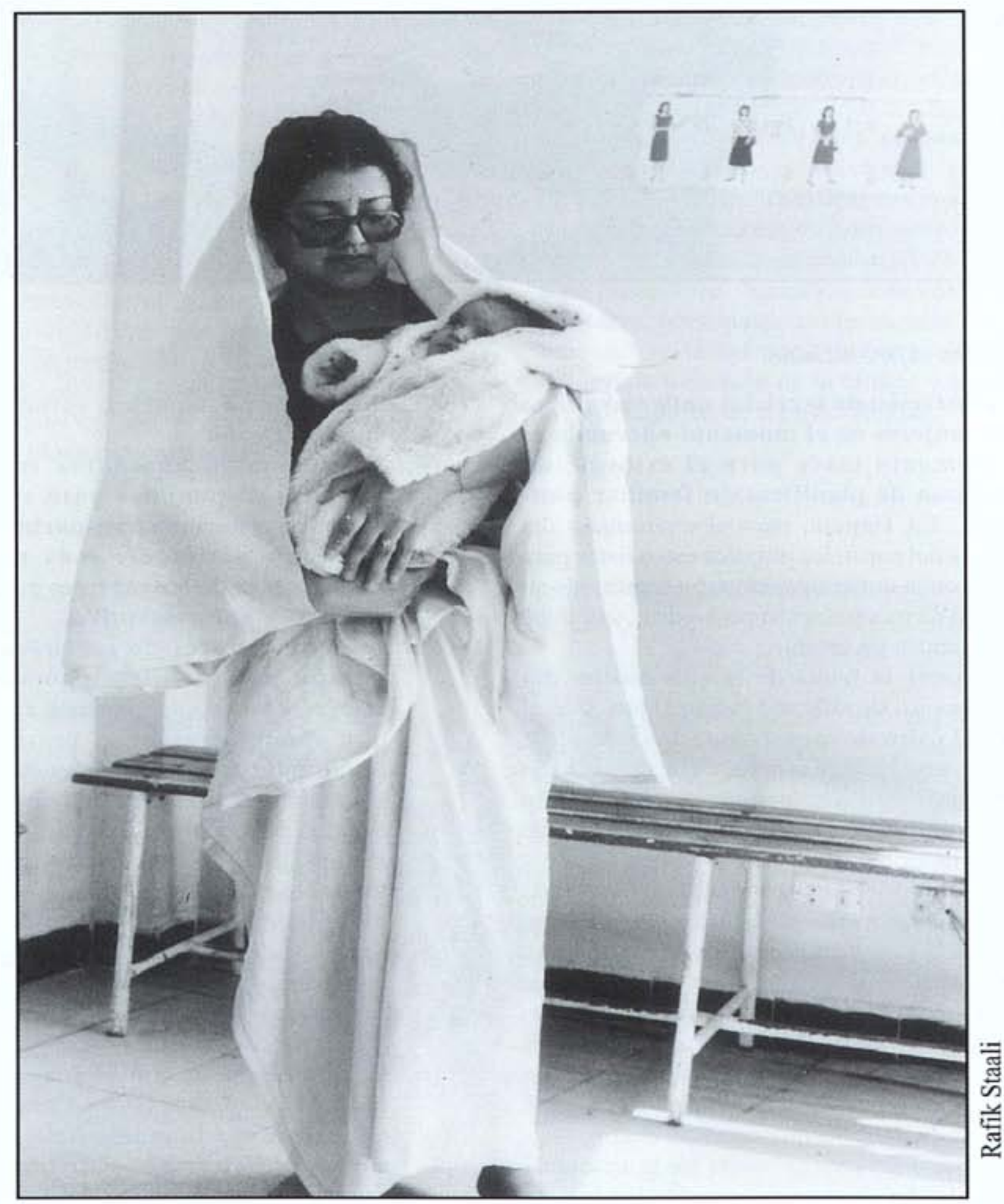




\section{FINALMENTE}

La historia del programa post-parto del cuarentavo día en Sfax, Túnez, sugiere, parafraseando el comentario de Tolstoi de que todas las familias felices son iguales, que las clínicas exitosas tienen importantes similitudes. Entre los atributos del programa, hay dos que sobresalen particularmente.

Primero, la asombrosa relevancia cultural de programar las visitas post-parto el cuarentavo dia después de parto, un día que tiene un significado especial para las madres y los nuevos bebés en una cultura islámica. Felizmente, este día se correlaciona bien con la recomendación médica occidental de una visita post-parto a las "seis semanas". El resultado es una fecha que las madres recuerdan fácilmente y, ya que está asociada con un importante evento post-parto que concierne tanto a la madre como al bebé, tiene sentido para ellas.

Mientras otras culturas pueden no tener observancias exactamente similares durante el periodo post-parto, es factible seguir el principio general de que la programación de las citas y los servicios deben "tener sentido" para la población que los recibe. Como se menciona en la introducción, es en este aspecto en el que tanto han fallado los servicios de anticoncepción postparto: la oferta de los servicios frecuentemente hecha uno o dos días después del parto, cuando las madres pueden estar menos interesadas en cómo prevenir otro embarazo o, para tal caso, en reanudar las relaciones sexuales.

La experiencia ha demostrado que tiene poco sentido ofrecer a las mujeres servicios anticonceptivos cuando aún se están recuperando de la experiencia inmediata del parto. Tiene mucho más sentido, como se puede observar en la impresionante aceptación de los servicios en la Maternidad de Sfax, ofrecer estos servicios en una fecha posterior, cuando las madres están empezando a restablecer el ritmo normal de sus vidas maritales.

Un segundo aspecto importante del programa de Sfax es el hecho de que los servicios están integrados. "Integración" aquí se refiere no sólo al hecho de que dos tipos de servicios se ofrecen en el mismo lugar (i.e., atención a la salud post-parto y planificación familiar), sino también a la integración de servicios para dos clientes: la madre y el bebé. Esta es quizás la innovación más importante del programa de Sfax. Una vez más, hace que la estrategia de prestación de servicios sea lógica desde el punto de vista del consumidor. Ya que una madre con un bebé recién nacido tendrá que llevar al bebé cuando vaya a recibir servicios para ella, es mucho más conveniente poder obtener todos los servicios de salud al mismo tiempo y en el mismo lugar. La madre ya no tiene que preguntarse dónde dejar al bebé, o si el bebé es bien recibido en la clínica. Además, el programa ha creado un doble incentivo para la utilización de los servicios: las madres quieren revisar la salud de sus bebés, así como usar los servicios de salud para ellas mismas.

En este sentido, otra vez, el programa de Sfax ha creado un servicio lógico y congruente con las necesidades de las madres. No sorprende entonces que el servicio sea bien aceptado por las madres. Sin embargo, un hecho que no debe ignorarse por defender el modelo de Sfax, es que la "doble" integración se facilitó porque una importante institución de salud, con una amplia gama de servicios médicos dentro de sus instalaciones, adoptó la innovación. Sería más difícil para un programa de planificación familiar intentar esta integración de ambos servicios de salud materno-infantil bajo un mismo techo. Esto apoya, quizás, el aumentar la conciencia entre los servicios de maternidad existentes sobre la necesidad de la planificación familiar post-parto y de acceso simultáneo a la atención para madres y recién nacidos.

A pesar del éxito del programa de Sfax, prevalecen notables problemas que son característicos de los programas post-parto en todo el mundo. Algunos de éstos parecen ser particulares del tipo de sistema creado en este programa, tales como el registro de datos "basado en el embarazo" en vez de "basado en la mujer". Esto significa que cada embarazo tiene su propia categoría, y una mujer que tiene dos o tres embarazos tendrá dos o tres gráficas que no están conectadas en el sistema de registro de datos.

Otras dificultades surgen de la rigidez normativa médica sobre la prestación de servicios 
de anticoncepción post-parto. Algunas de estas normas se relacionan con tratar de evitar que se den anticonceptivos a mujeres que están embarazadas. Ignoran, sin embargo, una buena cantidad de información biológica sobre los riesgos de embarazo para mujeres lactantes en el periodo de post-parto temprano. Se ha demostrado que estos riesgos son extraordinariamente bajos. Un programa que insiste en que una mujer debe menstruar para que pueda recibir ciertos tipos de anticonceptivos, está aumentando el riesgo de un embarazo no planeado entre sus clientes.

La falta de pastillas anticonceptivas adecuadas dentro del programa para madres lactantes subraya un problema que ha sido virtualmente universal en el enfoque post-parto sobre planificación familiar. Casi todas las descripciones de servicios post-parto de planificación familiar demuestran una peculiar omisión con respecto al tema de la lactancia. Esto puede muy bien ser el resultado de la subjetividad médica. Mucha de la asesoría técnica brindada a programas de planificación familiar proviene de personal clínico educado en paises desarrollados donde la lactancia ha sido menos universal y de menor duración que en los paises en desarrollo. Por lo general, el número de mujeres lactantes que solicitan planificación familiar es un porcentaje mucho menor de toda la clientela de planificación familiar en paises desarrollados que en el mundo en desarrollo. En los paises en desarrollo, una enorme mayoría de las mujeres que solicitan planificación familiar post-parto son madres lactantes.

Las mujeres lactantes requieren recomendaciones especificas sobre el momento y el tipo de anticoncepción, de manera que ésta no interfiera con la lactancia. Sin embargo, estas consideraciones están casi siempre ausentes de los materiales informativos, del diseño del programa, y de la selección de anticonceptivos. Esta falta de lógica con respecto a una muy importante caracteristica de muchas (si no todas) usuarias potenciales crea una disparidad básica entre los servicios ofrecidos y las necesidades de la clientela. Si se ajustan las políticas de servicios de anticoncepción para satisfacer las necesidades de las mujeres lactantes, podrá recibir los servicios una mayor proporción de mujeres. Esto incluye una mejor alineación de la normatividad del programa con información científica sobre la relación entre lactancia y fecundidad y la baja probabilidad de embarazo en el periodo de post-parto temprano. A medida que los programas reflejen una mejor apreciación de la fisiologia y el comportamiento de la mujer en el periodo post-parto, las madres tendrán mayor razón en percibir los servicios como lógicos, adecuados y completos.

Las necesidades de anticoncepción de las nuevas madres podrian satisfacerse mejor si el programa mismo tuviera la capacidad de diagnosticar y tratar al gran número de mujeres que se presentan con flujo vaginal, en vez de canalizarlas para tratamiento. Este servicio permitiria que muchas mujeres que desean anticonceptivos recibieran un método adecuado, en vez de que se les obligue a ir a otro lado para la consulta y regresar posteriormente, bajo riesgo de tener un embarazo no planeado en ese lapso. Además este servicio podria satisfacer de manera más efectiva las necesidades de salud de las mujeres, mediante la clasificación por infecciones comunes y prescribiendo el tratamiento correspondiente.

A la larga, otras clinicas y programas pueden aprender mucho de los aspectos del programa de Sfax asociados con altas tasas de utilización y buena aceptación de la planificación familiar. Los principios generales de la relevancia cultural y una lógica constelación de servicios están claramente ilustrados. Además, la historia de Sfax ilustra un hueco común en la prestación de servicios de muchas clínicas de planificación familiar post-parto: el descuidar las necesidades de las mujeres lactantes. Al abordar este tema en el futuro, otra importante proporción de mujeres en el periodo post-parto estarán mejor atendidas y podrán hacer mejor uso de los servicios de salud existentes. 


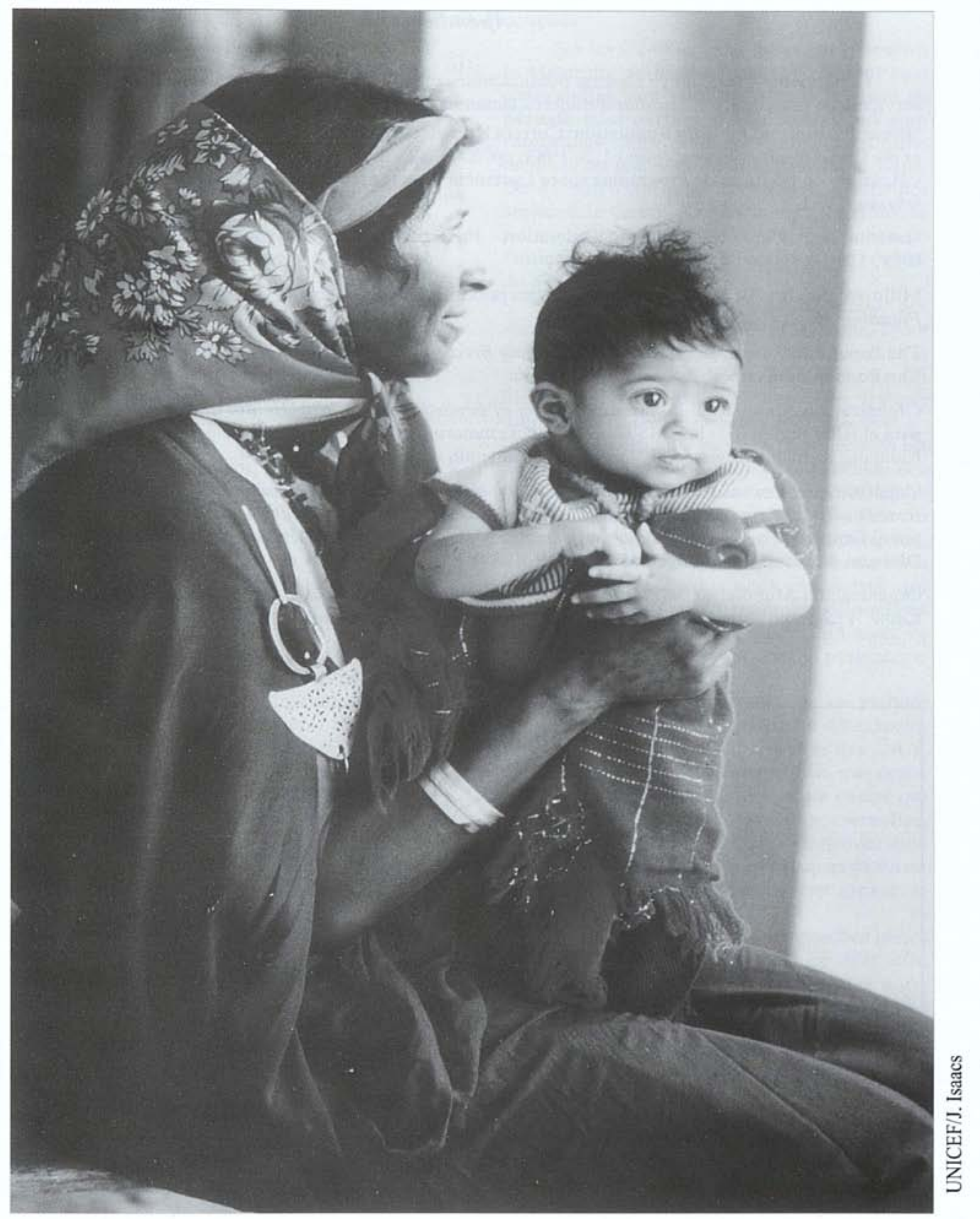




\section{Apéndice}

La siguiente lista incluye algunas publicaciones relacionadas especificamente con la prestación de servicios de planificación familiar a mujeres lactantes.

"Breastfeeding and Fertility Regulation: Current Knowledge and Program Policy Implications." Bulletin of the World Health Organization 61, 3, 1983: pp. 371-382. Informe de la reunión de WHO/NRC. Taller y Reunión de Políticas de Programas sobre Lactancia Materna y Regulación de la Fecundidad, Ginebra, febrero, 1982.

"International Planned Parenthood Federation. Breastfeeding, Fertility and Contraception (Londres: IPPF, 1984).

Millman, Sarah. "Breastfeeding and Contraception: Why the Inverse Association." Studies in Family Planning 16, 2, 1985: pp. 61-75.

The Population Council. Contraception During Breastfeeding: A Clinician's Sourcebook. (Nueva York: The Population Council, 1988).

Organización Mundial de la Salud. Patterns of Breastfeeding, Child, Health and Fertility. Preparado para el taller regional de la OMS sobre lactancia materna y fertilidad: procedimientos e informe, Hospital Kandang Kerbau, Universidad Nacional de Singapur, diciembre 10-14, 1984.

Organización Mundial de la Salud. Breastfeeding and Fertility: A Simplified Methodology for CommunityBased Calculations of the Proportion of Mothers at Risk of Conception by Breastfeeding Status. Pareparado por el Grupo de Trabajo en SMI sobre Lactancia Materna y Fertilidad, Unidad de Salud Materno-Infantil, División de Salud Familiar (Ginebra: OMS, 1987).

Organización Mundial de la Salud. Breastfeeding and Child Spacing: What Health Workers Need to Know. Programa sobre Salud Materno-Infantil y Planificación Familiar. (Ginebra: OMS, 1988). 


\section{Résumé en Français}

Ce numéro de Quality/Calidad/Qualité est consacré au programme du planning familial en période post-partum opérant au Centre de Maternité et Néonatologie de Sfax (Tunisie). Ce programne, developpé conjointement par l'Office National de la Famille et de la Population (ONFP) et le personnel de la Maternité, a été une réussite du fait qu'un nom- bre exceptionnel des mères soient retournées à la Maternité pour la visite, six semaines après l'accouchment. Ce taux élevé est premièrement dû à deux aspects du programme. Primo: le programme prodigue des soins pour le couple mère-enfant au même lieu et le même jour. Ceci répond au souci de la mère pour la santé de son nouveau-né, souci qui passe avant ses propres besoins.

Secondo: le rendez-vous est pris pour le quarantième jour après l'accouchement, car ce delai prend sa signification aussi bien dans la tradition que dans la religion. Dans la culture musulmane, le quarantième jour marque la fin de la convalescence de la mère. Ce même jour, elle reprend ses responsabilités familiales et peut apparaître en public pour la première fois après l'accouchement.

Pendant la visite du quarantième jour, un pédiatre procède à l'examen general du nouveauné. La vaccination en temps opportun est discuté avec la mère. Il lui est également conseillé d'allaiter son nourrisson au sein. En ce que concerne la mère, un examen gyné- cologique suivi d'une discussion sur divers problèmes de santé -y compris la santé reproductive - lui sont prodigués.

L'espacement des naissances est discuté et les services du planning familial sont offerts comme étant bénéfiques à la santé maternelle, assurant ainsi le developpement physique et mental de l'enfant.

Le Centre de Sfax offre des services tels que les ligatures des trompes, les DIUs, et les spermicides. Bien que disponibles, les contraceptifs orales sont rarement prescrits. Toutes les methodes sont disponibles à la visite du quarantième jour, sauf la sterilisation volontaire que peut être operée à partir du lendemain de la visite.

La cliente est informée du centre de planning familial le plus proche pour le suivi et la procuration des moyens contraceptifs.
Sur les 9.240 femmes qui ont accouchée à la Maternite de Sfax en 1987, 83,2 pour cent d'entre elles sont retournées pour la visite en période post-partum. Parmi celles qui sont retournées, 55,6 pour cent ont accepté une methode du planning familial pendant la visite. Dans le but d'améliorer davantage la qualité des services, le Centre de Sfax compte modifier sa politique afin qu'un plus grand nombre de femmes acceptent une methode pendant la visité du quarantième jour.

Une des possibilités serait de fournir des spermicides et des preservatifs aux femmes ayant des infections vaginales pour usage pendant la période de traitement. Ceci leur procure aussi bien une protection contraceptive, qu'une diminution de risque de propager l'infection.

Autre possiblité prise en considération est de mettre l'accent sur un usage plus étendu des contraceptifs orales. Le personnel medical hésite à donner les pilules contraceptives aux mères qui allaitent, par crainte des effets sur le nourrisson. Jusqu' à présent, les contraceptifs à basse dose de progestine recommendés aux mères qui allaitent ne sont pas suffisamment disponibles en Tunisie. Si ces pilules l'étaient, le Centre de Sfax pourrait les incorporer dans le programme post-partum.

Une revision de la politique en matiere d'insertion des DIUs est également à l'examen. En effet, ne peuvent se faire insérer des DIUs, lors de la visite du quarantième jour, que celles qui ont eu un rétour des règles ou celles qui déclarent ne pas avoir eu de relations sexuelles. Supprimer de telles restrictions permettrait à un plus grand nombre de femmes à risques d'utiliser la contraception, évitant ainsi une grossesse imprévue.

Ce ne sont que quelques approches prises en considération par le Centre de Sfax afin d'étendre les choix offerts aux clientes postpartum. Ceci fait partie des activités d'evaluations continues á travers lesquelles le programme cherche les moyens de mieux répondre aux besoins des soins de santé reproductive de ses clientes.

Une traduction de cet article entier est disponible en français. Si vous voulez recevoir la traduction, ecrivez à Ann Leonard, éditrice, Quality/Calidad/Qualité. The Population Council, One Dag Hammarskjold Plaza, New York, NY,10017, U.S.A. 



\section{Sobre las Autoras}

Francine Coeytaux es especialista en salud pública con amplia experiencia en el desarrollo y evaluación de programas de planificación familiar y salud reproductiva en África y Latinoamérica. Es Asociada del Population Council y ha sido responsable del desarrollo de las actividades del Council en África meridional y el inicio de un nuevo programa, a nivel mundial, para abordar el problema del aborto séptico e incompleto.

Beverly Winikoff es Asociada Médica Principal del Population Council y Co-Directora del Programa Ebert sobre asuntos críticos en salud reproductiva. Ella coordina los proyectos del Council sobre salud reproductiva y sobrevivencia infantil y tiene un especial interés en la lactancia materna y su relación con el espaciamiento de los embarazos y la salud infantil.

\section{Quality/Calidad/Qualité Comité de Asesores}

\author{
George Brown \\ Judith Bruce \\ Ethel Churchill \\ Francine Coeytaux \\ Adrienne Germain \\ Ann Leonard \\ Margaret McEvoy \\ John Paxman
}

\author{
Debbie Rogow \\ Jill Sheffield \\ Lindsey Stewart \\ Kerstin Trone \\ Gilberte Vansintejan \\ Beverly Winikoff \\ Margot Zimmerman
}

\author{
Diseño: Ann Leonard \\ Foto Portada: Bill Graham/Naciones Unidas \\ Formación e \\ impresión: mas impresos
}

Le invitamos a enviar sus comentarios y sus ideas sobre proyectos que pudieran ser incluidos en próximas ediciones de Quality/Calidad/Qualité. Si desea más copias de este ejemplar y le gustaría ser incluido en nuestra lista de envios, por favor escriba a: Ann Leonard, Editora, Quality/Calidad/Qualité, The Population Council, One Dag Hammarskjold Plaza, New York, NY, 10017 EU 


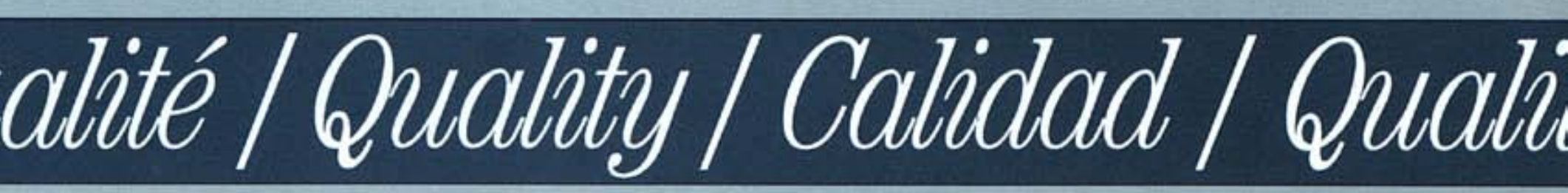

